\title{
Addition of Multilayer Urban Canopy Models to a Nonlocal Planetary Boundary Layer Parameterization and Evaluation Using Ideal and Real Cases
}

\author{
ERic A. Hendricks, JASON C. KNIEVEL, AND Yi WANG \\ National Center for Atmospheric Research, Boulder, Colorado
}

(Manuscript received 7 June 2019, in final form 2 July 2020)

\begin{abstract}
The multilayer urban canopy models (UCMs) building effect parameterization (BEP) and BEP + building energy model (BEM; a building energy model integrated in BEP) are added to the Yonsei University (YSU) planetary boundary layer (PBL) parameterization in the Weather Research and Forecasting (WRF) Model. The additions allow for the first analysis of the detailed effects of buildings on the urban boundary layer in a nonlocal closure scheme. The modified YSU PBL parameterization is compared with the other 1.5-order local PBL parameterizations that predict turbulent kinetic energy (TKE), Mellor-Yamada-Janjić and BougeaultLacarerre, using both ideal and real cases. The ideal-case evaluation confirms that BEP and BEP+BEM produce the expected results in the YSU PBL parameterization because the simulations are qualitatively similar to the TKE-based PBL parameterizations in which the multilayer UCMs have long existed. The modified YSU PBL parameterization is further evaluated for a real case. Similar to the ideal case, there are larger differences among the different UCMs (simple bulk scheme, BEP, and BEP+BEM) than across the PBL parameterizations when the UCM is held fixed. Based on evaluation against urban near-surface wind and temperature observations for this case, the BEP and BEP+BEM simulations are superior to the simple bulk scheme for each PBL parameterization.
\end{abstract}

\section{Introduction}

In comparison with the vegetation canopies, the urban canopy layer (UCL), defined as the layer of air beneath the mean height of buildings and trees (Oke 1976), has a much larger variability in roughness elements, and stark differences often exist in the albedo, evaporation, transpiration, and heat capacities among various surface types in residential, commercial, and industrial areas (Arya 2001; Liu et al. 2017). This heterogeneity leads to complex momentum and thermal forcing to the surface and boundary layers. With growing populations in urban areas globally, there is an increasing need to forecast accurately the mesoscale and microscale meteorological conditions there.

With limited computing power, current mesoscale numerical models typically cannot be executed quickly enough in real-time in a large-eddy simulation mode, whereby buildings and other turbulent UCL features and their feedbacks to the larger scale are explicitly resolved (Bauweraerts and Meyers 2019). Therefore, the common practice has been to use parameterizations in

Corresponding author: Eric A. Hendricks, erichend@ucar.edu order to represent the net effects of the sub-gridscale (SGS) urban processes on gridscale variables in mesoscale model simulations that are typically run with horizontal grid spacings of $1-10 \mathrm{~km}$. An urban canopy model (UCM) accounts for the aggregate effects of processes in the UCL and the energy and momentum exchanges there. In the Weather Research and Forecasting (WRF) Model (Skamarock et al. 2005), there is currently a hierarchy of UCMs available. The simplest parameterization is a bulk scheme, in which the thermal and momentum forcing of the urban area are accounted for by simple bulk formulas. The bulk scheme assumes uniformity in the urban morphology, with increases in roughness length and changes in the albedo and heat capacities/conductivities. A slightly more sophisticated parameterization is a singlelayer UCM (Kusaka et al. 2001; Kusaka and Kimura 2004). This UCM improves upon the bulk scheme by considering three different urban surface types (roof, wall, and road), and a diurnal profile of anthropogenic heat can be added. The third parameterization is a multilayer UCM that mimics the three-dimensionality of buildings, and solves the momentum and thermal forcings from walls, roofs, and roads (Martilli et al. 2002). This parameterization considers more sophisticated shadowing and 
radiation trapping effects and modifies the turbulent kinetic energy (TKE) prognostic equation and turbulent length scales to take into consideration the presence of buildings. The final parameterization is the building effect parameterization (BEP) combined with what is called the building energy model (BEM) in the WRF Model to take into account the heat exchanges between the interior of buildings and the surrounding environment (Salamanca et al. 2010). These processes are the heat diffusion through walls, roofs, and floors of buildings; natural ventilation and radiation exchange between indoor surfaces; heat generation due to human beings and equipment; and energy consumed by the air conditioning system. In addition to the papers above, some more details on each of these parameterizations are given by Salamanca et al. (2011) and Chen et al. (2011).

Currently, the bulk scheme and single-layer UCM can be run with any planetary boundary and surface-layer parameterizations in the WRF Model. Prior to this work, BEP and BEP+BEM were only implemented in two PBL parameterizations: Mellor-Yamada-Janjić (MYJ; Mellor and Yamada 1982; Janjić 1994) and the Bougeault-Lacarrere (BOU; Bougeault and Lacarrere 1989). A number of real-case modeling studies have been conducted using these PBL parameterizations with BEP and BEP+BEM (e.g., Salamanca et al. 2011, 2018; Gutiérrez et al. 2015; Barlage et al. 2016; Bauer 2020). Both the MYJ and BOU PBL parameterizations have 1.5-order closure, with separate prognostic equations for TKE and vertical diffusivities proportional to the TKE. A limitation of the local schemes is that they only account for mixing between adjacent vertical layers and thus do not account for mixing from large-scale deep eddies in convective PBLs (Xie et al. 2012). Over the years, nonlocal closure schemes have been developed that include a gradient adjustment term to account for nonlocal mixing (e.g., Deardorff 1972; Troen and Mahrt 1986; Hong and Pan 1996; Hong et al. 2006). Prior to the work described in this paper, $\mathrm{BEP}$ and $\mathrm{BEP}+\mathrm{BEM}$ were not implemented in any PBL parameterizations with nonlocal closure. The purpose of this paper is to describe the addition and demonstrate the potential usefulness of $\mathrm{BEP}$ and $\mathrm{BEP}+\mathrm{BEM}$ in a nonlocal closure PBL parameterization in the WRF Model: the YSU PBL parameterization (Hong et al. 2006). We will demonstrate that $\mathrm{BEP}$ and $\mathrm{BEP}+\mathrm{BEM}$ can be used to provide insight into how urban areas affect the UCL and PBL in nonlocal closure schemes, and that in many ways, the behavior of these UCMs is very similar to the behavior in local closure PBL schemes. In section 2, we describe the implementation of BEP and BEP+BEM in the YSU PBL parameterization. We examine the modified YSU
PBL scheme in ideal and real cases in sections 3 and 4, respectively. An interpretation of the principal results from the ideal and real simulations is given in section 5 , and the conclusions are given in section 6 .

\section{Addition of multilayer urban canopy models to the YSU PBL parameterization}

The current YSU PBL parameterization as implemented in the WRF Model is described by Hong et al. (2006). The routine solves a vertical diffusion equation (with vertical diffusivity, or eddy viscosity coefficient $K$ ), wherein nonlocal effects are accounted for by a correction term $\gamma_{c}$ to the local gradient, and there also exists an asymptotic flux term at the inversion layer $\overline{\left(w^{\prime} c^{\prime}\right)_{h}}(z / h)^{3}$ (wherein $w$ is the vertical velocity, $c$ is a state variable, $z$ is the physical height above ground, and $h$ is the PBL depth). This term is parameterized proportional to the jump of each variable at the inversion layer [Hong et al. 2006, their Eqs. [A.10(a)]-[A.10(d)]\}. With BEP and $\mathrm{BEP}+\mathrm{BEM}$ added to the YSU parameterization, a source term $S=A C+B$ is added to the right side that represents the forcing tendencies to the prognostic variables from the effects of buildings. The source term is split into an implicit component $A$ and an explicit component $B$. The modified YSU vertical diffusion equation for a prognostic variable $C$ with the inclusion of BEP and BEP+BEM source terms $A$ and $B$ is

$$
\frac{\partial C}{\partial t}=\frac{\partial}{\partial z}\left[K\left(\frac{\partial C}{\partial z}-\gamma_{c}\right)-\left(\overline{w^{\prime} c^{\prime}}\right)_{h}\left(\frac{z}{h}\right)^{3}\right]+A C+B .
$$

The $A$ and $B$ source terms are computed from the call to the $\mathrm{BEP}$ and $\mathrm{BEP}+\mathrm{BEM}$ subroutines in the land surface model in the urban imprint region, following the SGS parameterizations of Martilli et al. (2002) and Salamanca et al. (2010), for BEP and BEP+BEM, respectively. The source terms are linearly weighted between the urban and rural areas in the land surface model using the urban fraction $f$ [i.e., $B=(1-f) B_{r}+$ $f B_{u}$, where $B_{r}$ is the rural component and $B_{u}$ is the urban component from BEP or BEP+BEM], and thus Eq. (1) is solved at every horizontal grid point. BEP and $\mathrm{BEP}+\mathrm{BEM}$ provide net SGS tendencies of potential temperature $\theta$, zonal velocity $u$, meridional velocity $v$, and water vapor mixing ratio $q_{v}$. $\mathrm{BEP}$ and $\mathrm{BEP}+\mathrm{BEM}$ do not produce any tendencies of cloud water mixing ratio $q_{c}$ and ice mixing ratio $q_{i}$, so $A$ and $B=0$ for those prognostic variables. The finite-difference method for obtaining numerical solutions to Eq. (1) is given in the appendix.

Since the YSU PBL parameterization does not explicitly predict TKE, the modifications of Martilli et al. (2002) for the turbulence length scales, TKE 
production/dissipation, and associated changes to the vertical diffusivity are not added. The YSU PBL scheme does have diagnostic TKE (Shin et al. 2013), which is used when the topographic drag SGS parameterization (Jiménez and Dudhia 2012) is turned on. In the future, the BEP and BEP+BEM TKE source terms could be added to this scheme in order to improve the representation of frictional drag on cities in mountainous areas.

In the 1.5-order PBL schemes of MYJ and BOU, the BEP and BEP+BEM TKE tendencies and turbulent length scale modifications directly change the local vertical diffusivities in the PBL above the surface. In the YSU PBL scheme, the vertical diffusivities are also modified, but in a different way. The YSU scheme has separate vertical diffusivities for momentum $K_{m}$ and temperature/moisture $K_{t}$. These diffusivities take the functional forms (Troen and Marht 1986; Noh et al. 2003; Hong et al. 2006)

$$
\begin{aligned}
K_{m} & =k w_{s} z\left(1-\frac{z}{h}\right)^{p} \text { and } \\
K_{t} & =K_{m} \operatorname{Pr}^{-1},
\end{aligned}
$$

where $k$ is the von Kármán coefficient, $w_{s}$ is the mixedlayer velocity scale, $z$ is the height from the surface, $h$ is the PBL height, $p=2$ is a profile shape exponent, and $\operatorname{Pr}$ is the Prandtl number. The mixed-layer velocity scale is

$$
w_{s}=\left(u_{*}^{3}+\phi_{m} k w_{* b}^{3} z / h\right)^{1 / 3},
$$

where $u_{*}$ is the friction velocity, $\phi_{m}$ is a wind profile function, and the convective velocity scale for moist air is $w *_{b}=\left[\left(g / \theta_{v a}\right)\left(w^{\prime} \theta_{v}^{\prime}\right)_{0} h\right]^{1 / 3}$. When BEP and BEP+BEM are active, the surface fluxes are a linear combination of the urban and rural fluxes using the same weighting function described above. Thus, BEP and BEP+BEM directly modify $\left(w^{\prime} \theta_{v}^{\prime}\right)_{0}$ when the urban fraction is greater than zero, which in turn modifies $w_{s}$ and finally the amplitudes of $K_{m}$ and $K_{t}$. These fluxes also modify the gradient correction term $\gamma_{c}$,

$$
\gamma_{c}=b \frac{\overline{\left(w^{\prime} c^{\prime}\right)_{0}}}{w_{s 0} h}
$$

where $\left(w^{\prime} c^{\prime}\right)_{0}$ is the surface flux for momentum or potential temperature ( $\gamma_{c}$ is not used for water vapor) and $b$ is a coefficient of proportionality.

In summary, in the YSU, MYJ, and BOU PBL parameterizations, $\mathrm{BEP}$ and $\mathrm{BEP}+\mathrm{BEM}$ impact the respective vertical diffusion equations through near-surface source term forcing and modification of the vertical diffusivities. One important difference is that in YSU, the amplitude of the entire vertical diffusivity profile is modified in response to the surface fluxes (which in turn are modified by BEP and BEP+BEM forcing), while in MYJ and BOU, TKE also modifies the vertical diffusivity locally. Unique to the implementation in the YSU PBL parameterization, the BEP and BEP+BEM source terms contribute to the gradient correction term $\gamma_{c}$ through modification of the surface fluxes. In the next section, we will examine the behaviors of the vertical mixing in all PBL parameterizations.

\section{Ideal-case numerical simulations}

\section{a. Model setup}

Before evaluating the modified YSU PBL parameterization against a real case, we first evaluate the parameterization in an idealized urban heat island (UHI) scenario. The WRF Model (Skamarock et al. 2005), version 4.1, is used for the numerical simulations. In this scenario, an urban patch of commercial and industrial (COI) land use is placed in the center of the domain, and the patch heats up from solar radiation, generating rising motion and a secondary circulation. For this setup, a square domain of $60 \mathrm{~km} \times 60 \mathrm{~km}$ is used with uniform $1-\mathrm{km}$ horizontal grid spacing. The central latitude is $23.3^{\circ} \mathrm{N}$, and central longitude is $0^{\circ}$. The Coriolis force is active. The entire domain has a land use of grasslands, except in the center, where a $10 \mathrm{~km} \times 10 \mathrm{~km}$ patch of COI land use exists (urban fraction of 0.95). The model top is at $8 \mathrm{~km}$, and 51 levels are used on a stretched grid. For close inspection of surface and boundary layer processes, 38 of these levels are below $2 \mathrm{~km}$. A model time step of $10 \mathrm{~s}$ used. Sixth-order explicit diffusion is used to damp 2- $\Delta x$ waves (Knievel et al. 2007). The set of physical parameterizations used are the Dudhia shortwave radiation parameterization (Dudhia 1989), the rapid radiative transfer model (RRTM) longwave parameterization (Iacono et al. 2008), the unified Noah land surface model (Ek et al. 2003; Tewari et al. 2004), and the double-moment 5-class microphysical parameterization (Lim and Hong 2010). To assess the modified YSU PBL parameterization, it is compared to both the MYJ and BOU parameterizations. Both of the latter PBL parameterizations have been tested with BEP and $\mathrm{BEP}+\mathrm{BEM}$ in both ideal and real cases. For rural areas, the eta similarity scheme (Janjic 1994) is used with the MYJ and BOU PBL parameterizations, while the revised MM5 parameterization (Jiménez et al. 2012) is used with the YSU PBL parameterization. The latter scheme is a revised surface-layer formulation that covers the full range of atmospheric stabilities. Note that in the WRF Model, it is required to use these different surfacelayer schemes between the MYJ/BOU and YSU PBL 

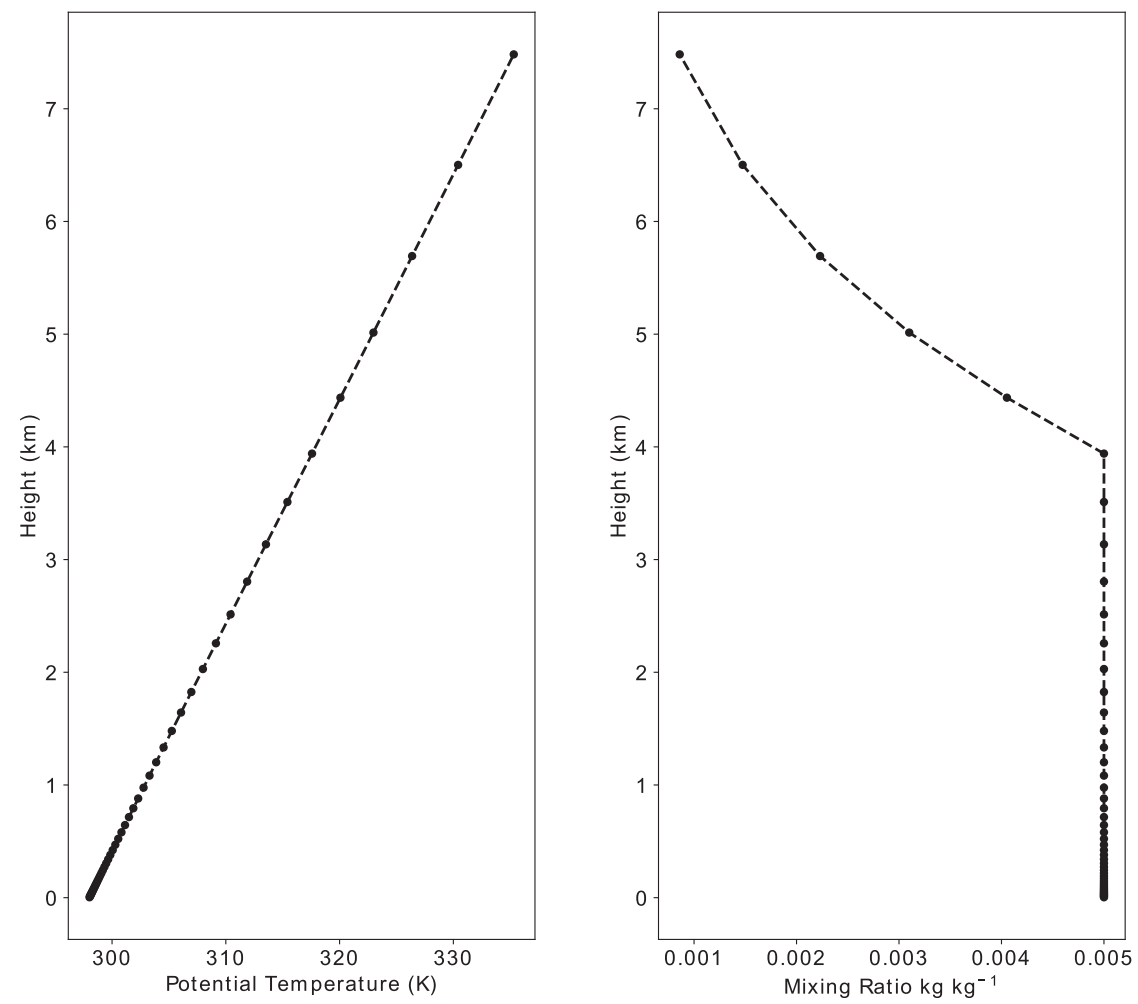

FIG. 1. Ideal-case initial soundings of (left) potential temperature and (right) water vapor mixing ratio. The initial winds are zero. In both plots the WRF Model's vertical levels are marked by black dots.

parameterizations. The WRF Model's default urban parameter table is used for the UCMs, which specifies a number of parameters as a function of low-intensity residential (LIR), high-intensity residential (HIR), and $\mathrm{COI}$ urban classes. BEP and BEP+BEM are run on a vertical grid with a vertical spacing of $5 \mathrm{~m}$ and 18 levels.

The initial conditions consist of a stably stratified atmosphere with zero winds, and with moisture confined to low levels. The potential temperature increases linearly from $298 \mathrm{~K}$ at the surface to $338 \mathrm{~K}$ at $z=8 \mathrm{~km}$. The mixing ratio is $5 \mathrm{~g} \mathrm{~kg}^{-1}$ below $z=4 \mathrm{~km}$ and decreases to zero at $z=8 \mathrm{~km}$. The vertical profiles of the initial potential temperature and mixing ratio are given in Fig. 1. The lateral boundary conditions are periodic in both the $x$ and $y$ directions. The simulations are run for $24 \mathrm{~h}$ and initialized at 0500 local time (LT) on 1 June.

\section{b. Results}

Before examining the simulations with the COI patch, we first perform a study of varying the fractional impervious surface area (ISA) of the central patch in the range $0.00,0.25,0.50,0.75$, and 1.0. The purpose of the study is to examine the sensitivity of the results to a wide range of ISAs and to motivate where the COI urban class exists in the range of different ISAs. The YSU
$\mathrm{BEP}+\mathrm{BEM}$ simulation is used for the study. In Fig. 2, time series of spatially averaged quantities (over the central patch and below $z=1 \mathrm{~km}$ ) are given. The vertical diffusivity of heat increases in the day with increasing ISA due to larger sensible heat fluxes (Fig. 2a). There are also higher potential temperatures with increasing ISA (Fig. 2b). In the day (0600-1800 LT), there are higher water vapor mixing ratios with decreasing ISA due to the higher latent heat fluxes from vegetated areas (Fig. 2c). In the evening and night (1800-0000 LT), the mixing ratios in the ISA $=0.25-1.00$ simulations are similar to each other, while the ISA $=0.00$ simulation has mixing ratios that are $0.5 \mathrm{~g} \mathrm{~kg}^{-1}$ lower than the other simulations. The increased near-surface moisture content (or urban moisture excess) in the evening for higher ISA simulations is consistent with observations (Hage 1975; Ackerman 1987; Kuttler et al. 2007) and due to the increased vertical moisture flux convergence, which increases rapidly from large negative daytime values at 1800 LT (not shown).

Having shown the relationship of the COI patch simulation to simulations with varying ISA, we now focus on the behaviors of the modified YSU PBL vertical diffusion Eq. (1) with BEP and BEP+BEM source terms near the surface. In the top-left panel of Fig. 3, 
a)

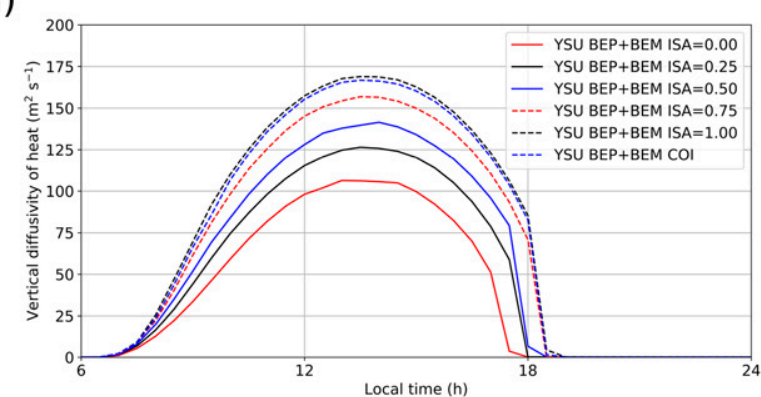

b)

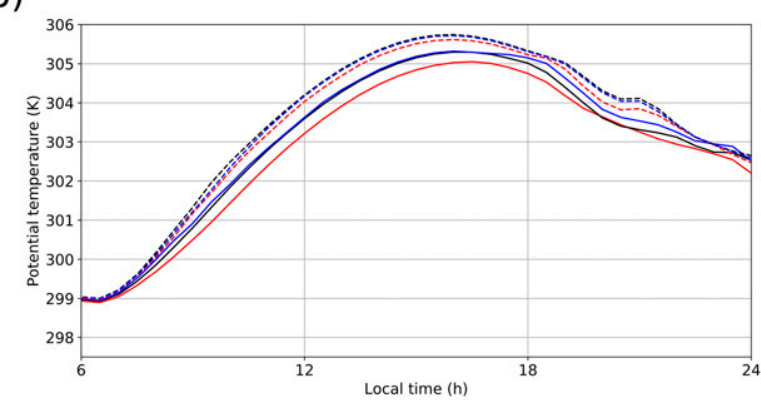

c)

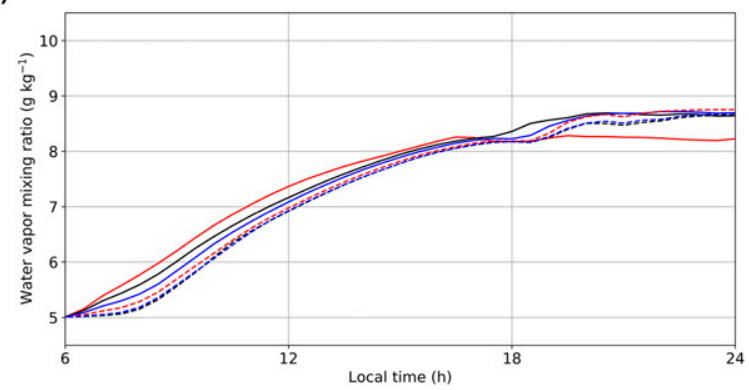

FIG. 2. Results of the ISA study: (a) vertical diffusivity of heat $\left(\mathrm{m}^{2} \mathrm{~s}^{-1}\right),(\mathrm{b})$ potential temperature $(\mathrm{K})$, and (c) water vapor mixing ratio $\left(\mathrm{g} \mathrm{kg}^{-1}\right)$. All variables are averaged over the central patch and below $z=1 \mathrm{~km}$.

the explicit component $B$ for potential temperature is larger in the COI urban patch than in the environment because of the stronger surface heating there. This causes differential warming, whereby the near-surface potential temperature is higher in the urban patch than in the rural environment (Fig. 3, top-right panel). The differential heating generates a secondary thermally direct circulation. Flow toward the central patch develops in response to the heating, equating to low-level convergence (Fig. 3, middle-right panel). The enhanced frictional drag from BEP+BEM over the urban patch resists this inward flow, which is evident with the explicit $B$ component being directed outward (Fig. 3, middle-left panel). The moisture sources are larger in the rural environment than in the urban patch (Fig. 3, bottom-left panel), causing a lower near-surface moisture content over the urban patch in comparison with the rural environment
(Fig. 3, bottom-right panel). Note, however, that nearsurface moisture content increases over the whole domain in response to the convergence and urban and rural sources. These results demonstrate that modified YSU vertical diffusion solvers for momentum, potential temperature, and moisture produce expected behaviors at the surface.

We next examine the near-surface BEP and $\mathrm{BEP}+\mathrm{BEM}$ thermal forcing in a thin near-surface layer from $z=0-20 \mathrm{~m}$ in the YSU simulations and compare and contrast the forcing in the MYJ and BOU simulations. In Fig. 4a, time-height depictions of the evolution of the explicit component $B$ for potential temperature below $z=20 \mathrm{~m}$ are given for each of the PBL parameterizations with BEP and BEP+BEM. The level of $20 \mathrm{~m}$ is chosen because it is near the peak building height in the default urban parameter input table, and thus the vertically distributed sources in BEP and BEP+BEM are mostly located below this level. The evolution of $B$ is similar in each PBL scheme, with the strongest forcing near the surface and decay to near zero at $z=20 \mathrm{~m}$. For each PBL scheme, the $B$ forcing is stronger with $\mathrm{BEP}+\mathrm{BEM}$ than with BEP only because of the added heating from the interior building processes such as waste heat from air conditioning $(\mathrm{A} / \mathrm{C})$ systems. The $\mathrm{BEP}+\mathrm{BEM}$ forcing also continues into the evening and night (after 1700 LT), whereas the BEP thermal forcing ends at $1700 \mathrm{LT}$. The effects of the surface forcing on the near-surface potential temperature evolution are evident in Fig. 4b. The MYJ and YSU simulations have similar evolutions during the day, and the BOU simulation reaches a significantly higher $(2 \mathrm{~K})$ peak potential temperature. At night, the added heating from BEM causes higher potential temperatures over the BEP simulations (by approximately $2 \mathrm{~K}$ ) for each PBL parameterization.

Next, we examine how the surface heating affects the PBL structures in each simulation. In Fig. 5, cross sections of the divergence are given at $1700 \mathrm{LT}$ with potential temperature contours overlaid. The cross sections show convergence below $z=1.5 \mathrm{~km}$ and divergence between approximately $z=1.5-2.7 \mathrm{~km}$. Above the dry convection, internal gravity waves are evident in response to the convection penetrating the stable layer above. In each simulation the higher heating over the urban patch in comparison to the nearby rural environment causes a secondary thermally direct circulation to develop in the PBL. The BEP+BEM simulations have $0.5-1.0-\mathrm{K}$ higher potential temperatures near the surface than the BEP simulations (across all PBL parameterizations) and there are only minor differences through the depth of the PBL. The YSU simulations have smoother cross sections than the MYJ or BOU simulations. The thermally direct 

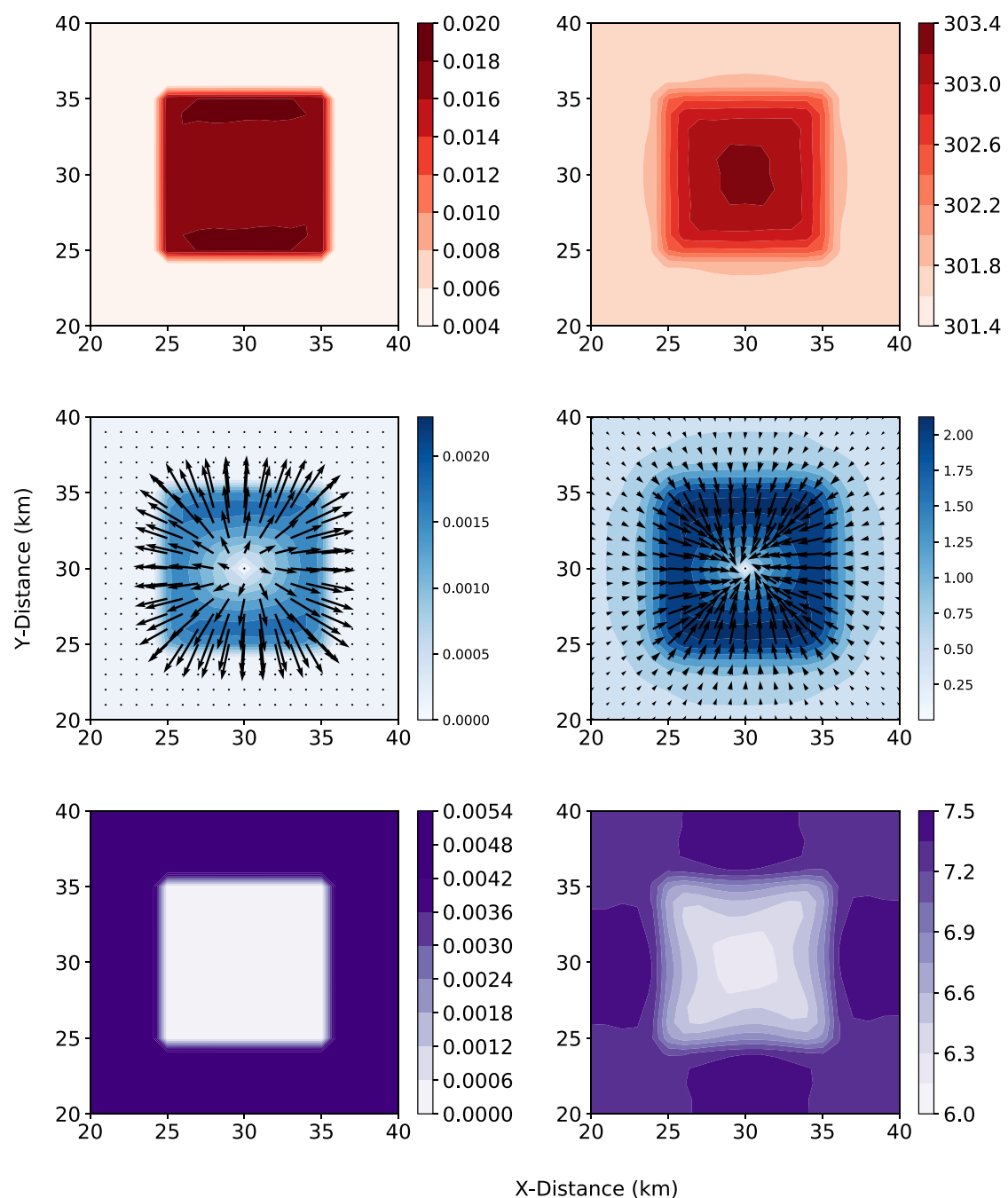

FIG. 3. BEP+BEM near-surface forcing at $z=3.57 \mathrm{~m}$ and state variable response in the modified YSU PBL parameterization: (top left) Explicit component $B$ for the potential temperature $\left(\mathrm{K} \mathrm{s}^{-1}\right)$, (top right) potential temperature $(\mathrm{K})$, (middle left) magnitude and overlaid vectors for explicit component $B$ for the horizontal velocity $\left(\mathrm{m} \mathrm{s}^{-2}\right)$, (middle right) magnitude and overlaid vectors of the horizontal velocity $\left(\mathrm{m} \mathrm{s}^{-1}\right)$, (bottom left) explicit component $B$ for the mixing ratio $\left(\mathrm{g} \mathrm{kg}^{-1} \mathrm{~s}^{-1}\right)$, and (bottom right) mixing ratio $\left(\mathrm{g} \mathrm{kg}^{-1}\right)$. All variables are averaged from 0500 to $1700 \mathrm{LT}$.

circulation in the YSU BEP and BEP+BEM simulations is approximately $0.25 \mathrm{~km}$ deeper than in the MYJ or BOU simulations. The mixing ratio cross sections (not shown) do not exhibit significant variability among the different simulations.

To further understand the PBL structures, we examine the vertical mixing in each of the six simulations. In Fig. 6, time-height shaded contour plots of the vertical diffusivity of heat (similar structures exist for the vertical diffusivity of momentum) are shown over the central urban patch. For both BEP and BEP+BEM, the BOU simulations have the highest diffusivities, followed by the YSU simulations, followed by the MYJ simulations.
The MYJ and BOU simulations have higher frequency variations in the vertical diffusivities in time and in the vertical than the YSU simulation. This effect is due to the local TKE variations in the MYJ and BOU simulations. The effect is less in the BOU simulation because it includes a gradient correction term to account for vertical mixing by large eddies. Although this term is much less sophisticated than the gradient correction term in the YSU PBL parameterization (Xie et al. 2012), it may explain some of the similarities in the qualitative structure of vertical diffusivities between the schemes. For each PBL parameterization, the BEP+BEM simulations have approximately $5 \%$ higher peak values of the 


\section{a)}
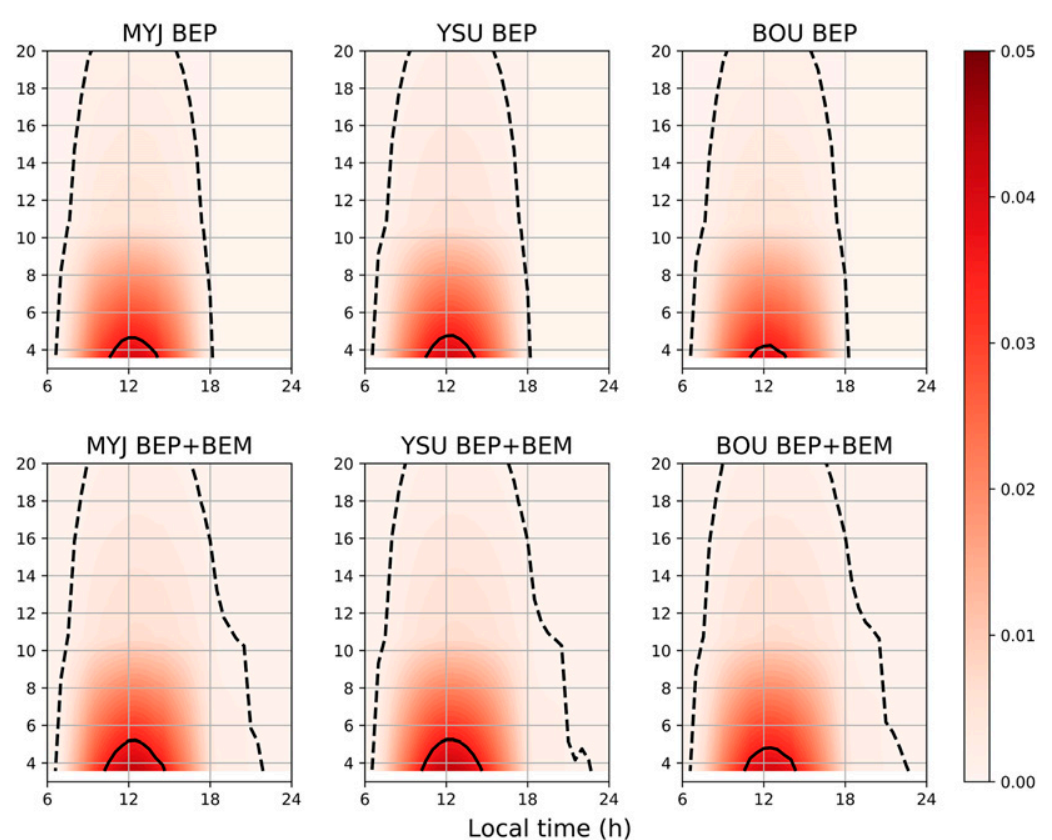

b)

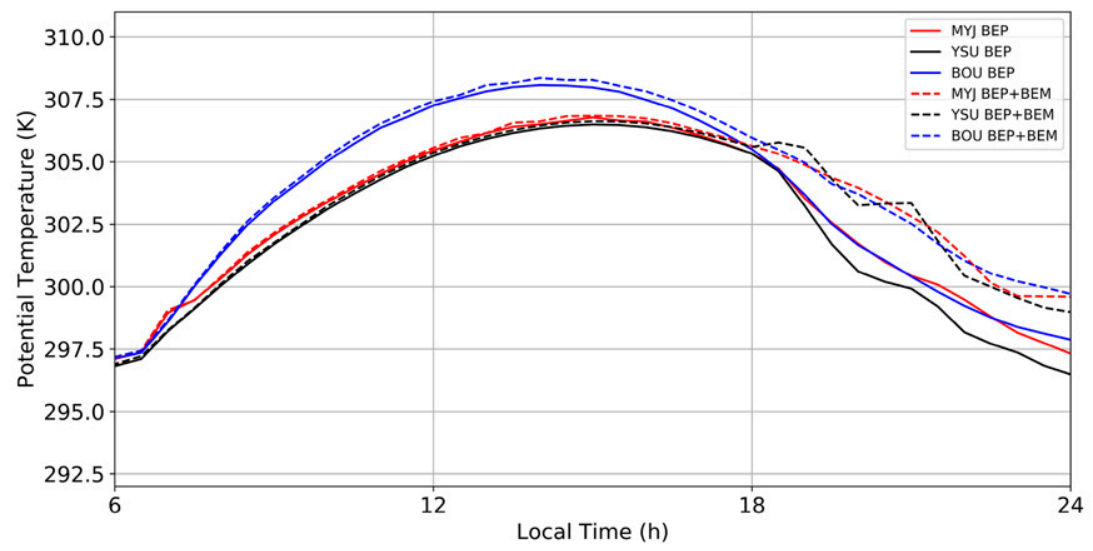

FIG. 4. (a) Time-height evolution of the near-surface explicit component BEP and $\mathrm{BEP}+\mathrm{BEM}$ source term $B$ for potential temperature $\left(\mathrm{K} \mathrm{s}^{-1}\right)$, and (b) time evolution of the spatially averaged (below $z=30 \mathrm{~m}$ and within central patch) potential temperature. In (a), the 0.001 contour is in dashed black to help illustrate the BEP+BEM heating into the night, and the 0.035 contour is in solid black to help illustrate the higher surface heating in the day.

vertical diffusivities than the BEP simulations due to the added surface heating in the BEP $+\mathrm{BEM}$ simulations. In Fig. $7 \mathrm{a}$, profiles of virtual potential temperature $\theta_{v} \approx$ $\theta\left(1+0.61 q_{v}\right)$ evolutions at 0900,1300 , and $1700 \mathrm{LT}$ are given, depicting the daytime growth of the mixed layer from the initially stable sounding $\left(\theta_{v}\right.$ is used because it is the standard variable for assessing stability). The $\mathrm{BEP}+\mathrm{BEM}$ simulations have virtual potential temperatures that are $0.05-0.10 \mathrm{~K}$ higher than the BEP simulations for all PBL parameterizations but similar stabilities. At $0900 \mathrm{LT}$, the YSU simulations are more stable than the BOU or MYJ simulations. At 2300 LT
(Fig. 7b), the surface cooling has stabilized the PBL right near the surface, while the mixed layer still exists above. In comparison to BEP, the BEP+BEM simulations have higher temperatures right near the surface as well as a thin unstable layer.

We also examine the behavior of the gradient correction term in the modified YSU PBL scheme. As discussed earlier, the YSU PBL scheme includes a gradient correction term $\gamma_{c}$ to account for nonlocal mixing by large eddies, and the term is parameterized based on the surface fluxes. Figure 8a shows the vertical profile of potential temperature over the urban patch with and 

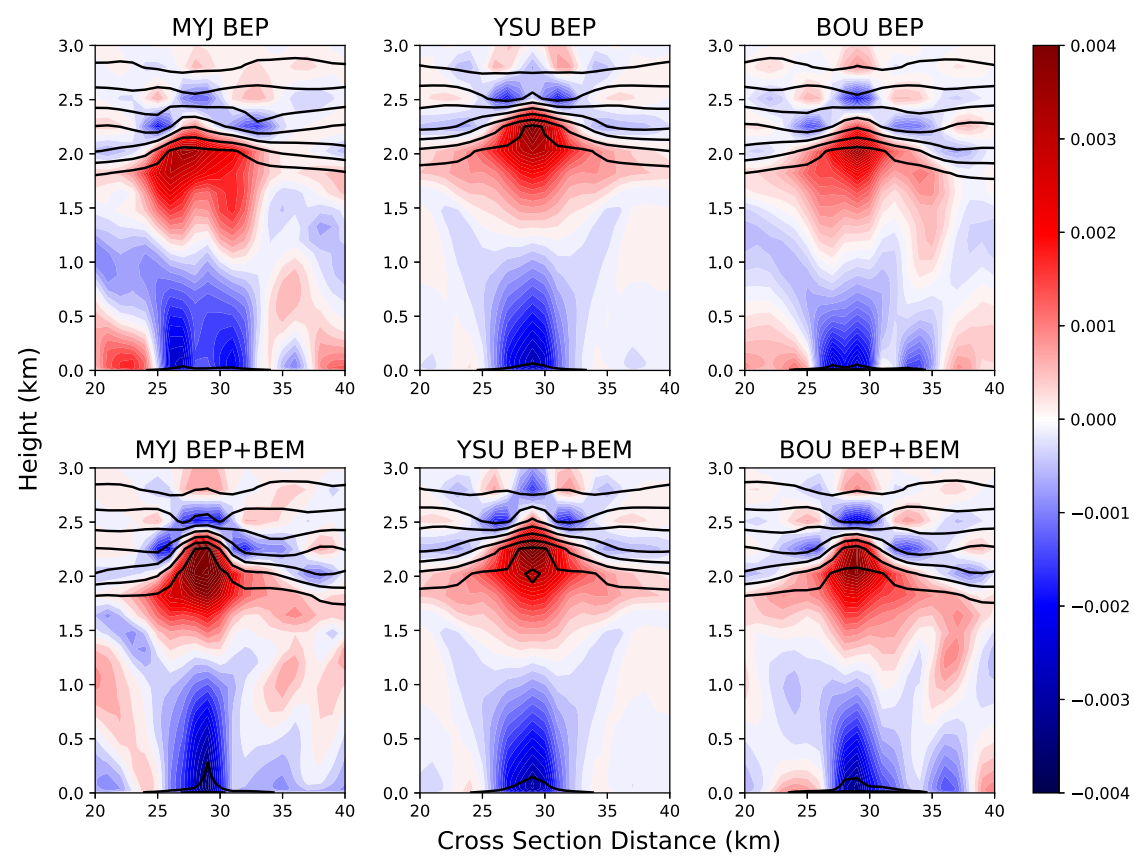

FIG. 5. West-east cross sections of divergence $\left(\mathrm{s}^{-1}\right)$ through the central COI patch at 1700 LT for all simulations. The potential temperatures are overlaid in black contours. The contour near the surface is $306 \mathrm{~K}$. The contours at the top of the PBL are $306-312 \mathrm{~K}$ in $1-\mathrm{K}$ increments moving upward.

without this term in simulations based on the YSU "bulk," BEP, and BEP+BEM parameterizations at 1300 LT. The behavior is similar among all simulations, with the gradient correction term reducing the mixed-layer vertical gradient of potential temperature. Figure $8 \mathrm{~b}$ shows the same vertical profiles at the surface. In all UCMs, the near-surface potential temperatures with the gradient correction term are approximately $0.25 \mathrm{~K}$ lower than the potential temperatures without the term. The urban heat fluxes are largest in the $\mathrm{BEP}+\mathrm{BEM}$ simulation, followed by the BEP simulation, followed by the bulk simulation. The potential temperatures at the surface and in the mixed layer are largest in the BEP+BEM simulations. The gradient correction term has a similar magnitude effect for each UCM. The results of the simulations are consistent with Fig. 7 of Hong et al. (2006): nonlocal mixing of heat from largescale eddies warms the upper part of the PBL and makes the lower part more stable.

\section{c. Synthesis of results from ideal-case simulations}

In these simulations of an ideal case, the modified YSU vertical diffusion equation solvers for momentum, potential temperature, and mixing ratio with BEP and $\mathrm{BEP}+\mathrm{BEM}$ source terms produce expected behaviors near the surface. YSU's vertical diffusivity behaves as expected in response to surface heating from BEP and
$\mathrm{BEP}+\mathrm{BEM}$. The gradient correction term in YSU behaves similarly with added BEP forcing as in the simple bulk scheme, and we can qualitatively replicate Fig. 7 of Hong et al. (2006) with this forcing. There are many similarities in the near-surface response and mixedlayer growth in the YSU PBL scheme with BEP and $\mathrm{BEP}+\mathrm{BEM}$ forcing in comparison to the MYJ and BOU schemes. Differences among the PBL parameterizations with $\mathrm{BEP}$ or $\mathrm{BEP}+\mathrm{BEM}$ are relatively minor. Although the vertical diffusivities are different among the different PBL parameterizations (Fig. 6), one possible explanation for the similarities is that the $\mathrm{BEP}$ and $\mathrm{BEP}+\mathrm{BEM}$ surface forcing effect dominates the vertical mixing effect near the surface. Additionally, the local vertical diffusivities near the surface are similar among the PBL parameterizations. Having evaluated the modified YSU PBL scheme in an ideal scenario, we now examine the behaviors of the scheme in a more complex real case.

\section{Real-case numerical simulations}

\section{a. Model setup}

The WRF Model, version 4.1, is also used for the numerical simulations of the real case. We use three domains with $298 \times 298$ grid points and respective 

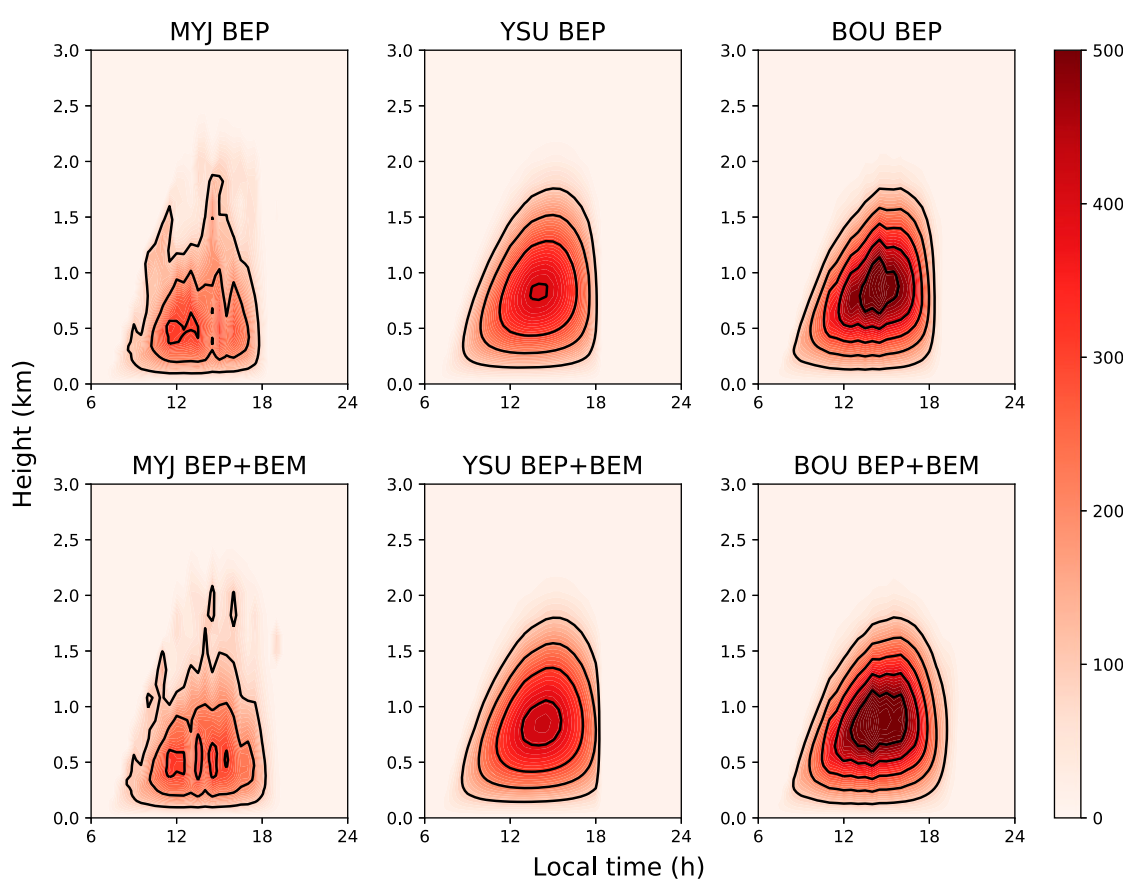

FIG. 6. Time-height evolution of the average vertical diffusivity of heat $K_{t}\left(\mathrm{~m}^{2} \mathrm{~s}^{-1}\right)$ over the central urban patch for all six simulations. Black contours are shown at intervals of $100 \mathrm{~m}^{2} \mathrm{~s}^{-1}$. The vertical diffusivity of momentum has similar vertical structures.

spacings of 9,3 , and $1 \mathrm{~km}$. The innermost domain covers Houston, Texas, and the nearby environment, the middle nested domain covers a large part of southeastern Texas and the Gulf of Mexico, and the outermost domain covers the southern and central United States and northern Mexico (Fig. 9a). Zooming in to domain 3 (Fig. 9b), the land-use index is shown for the Houston metropolitan area and nearby rural environment. The land-use index values are from the 33 Modified International Geosphere-Biosphere Programme (IGBP) MODIS Noah land-use categories and are listed in Table 1. The Houston metropolitan area consists of regions of category 31 (LIR), 32 (HIR), and 33 (COI). To the west and south of Houston the green areas are wetlands and croplands. The blue and purple values to the northeast of Houston are shrublands and forests.

A 20-s coarse-grid time step is used for the simulations. For enhanced vertical resolution in the planetary boundary layer, 60 levels are used between the surface and the model top at $10 \mathrm{hPa}$, using the WRF Model's standard stretched grid with finer resolution near the surface. The lowest model level is approximately $24 \mathrm{~m}$, and 15 levels are used below $3 \mathrm{~km}$. To capture the temporal variations in the urban area, variables are written out every $10 \mathrm{~min}$ on domain 3 . The physical parameterizations are the WSM 6-class microphysical parameterization (Hong and Lim 2006), rapid radiative transfer model for GCMs (RRTMG) longwave and shortwave radiation parameterizations, and the unified Noah land surface model. On domain 1 (with 9-km grid spacing), the new Tiedtke cumulus parameterization (Tiedtke 1989; Zhang et al. 2011) is used to help represent the effects of SGS convection, while convection is calculated explicitly on the innermost two domains. The simulations are initialized using the NCEP GDAS final analysis at a $0.25^{\circ}$ horizontal grid interval, and the lateral boundary conditions are updated at intervals of $3 \mathrm{~h}$. The same physical parameterizations above are used in the ideal numerical experiments.

Although it is not possible to test the modified YSU PBL parameterization in every possible range of conditions, we have elected to test the scheme for a real case in the autumn when approximately equal amounts of day and night exist. These simulations are initialized at 0000 UTC 5 October 2017 and run until 0000 UTC 7 October 2017. The case is a relatively simple synoptic situation, in which the weather in Houston is dominated by the sea breeze and land breeze. In the future, we also plan to examine the modified scheme in more complex weather situations, such as cold outbreaks, frontal passages, heat waves, and hurricane landfalls. However, the present case is sufficient to demonstrate that the modified YSU scheme produces results in a real case similar to the results of the MYJ and BOU schemes and provides insight into urban effects on the PBL in these scenarios. 
a)

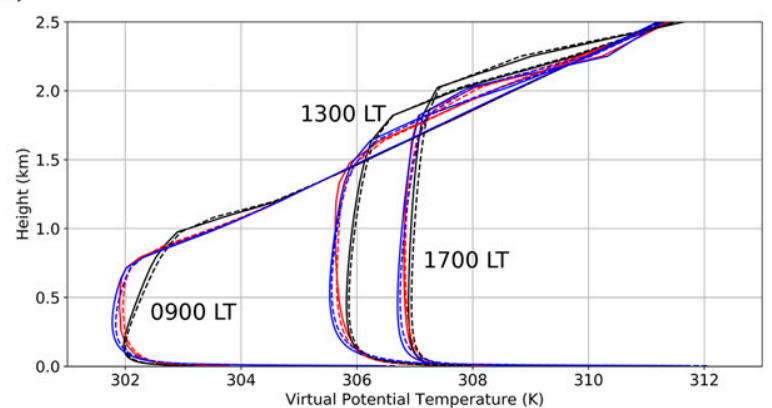

b)

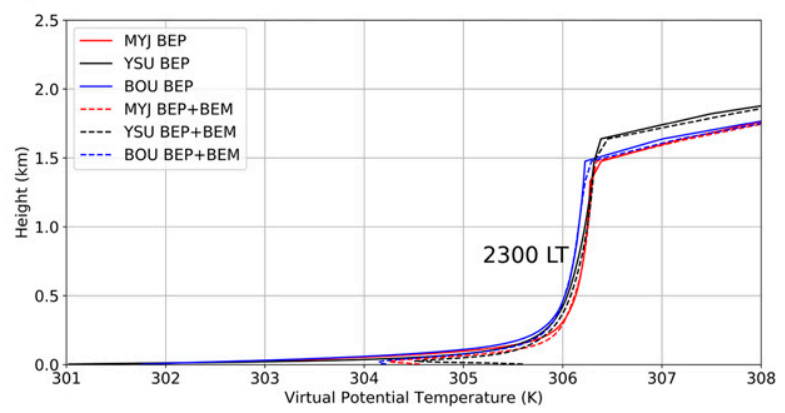

FIG. 7. Vertcal profiles of virtual potential temperature $\theta_{v}$ (K) averaged over the central patch at different times: (a) 0900, 1300, 1700, and (b) 2300 LT.

For the execution of the WRF Model with the singlelayer UCM, BEP, and BEP+BEM, the National Urban Data and Access Portal Tool (NUDAPT-44) dataset is used (Ching et al. 2009; Chen et al. 2011). The NUDAPT-44 dataset has all the urban morphological characteristics of Houston, including urban fraction, impervious fraction, building height histograms, building plan area fraction, building height weighted by footprint plan area, and building surface-area-to-planarea ratio. For the purposes of this study, NUDAPT is sufficient; however, simulations accounting for the 10 local climates zones in Houston in the World Urban Data and Access Portal Tool (WUDAPT) dataset (Stewart and Oke 2012; Ching et al. 2018; Hammerberg et al. 2018) would be useful for future work. WUDAPT has not yet been released in the official WRF Model repository, but it is expected to be released there in the near future.

The urban canopy parameterizations also require material characteristics of the roofs, walls, and roads. These parameters include thermal conductivities, specific heats, emissivities, albedos, and roughness lengths, and are listed in Table 2. A key parameter for $\mathrm{BEP}+\mathrm{BEM}$ is the waste heat from $\mathrm{A} / \mathrm{C}$ systems. In LIR and HIR regions, effects from $\mathrm{A} / \mathrm{C}$ systems were turned on in the evening and night (from 1700 to $0900 \mathrm{LT}$ ), whereas in the COI area effects from $\mathrm{A} / \mathrm{C}$ systems were a)

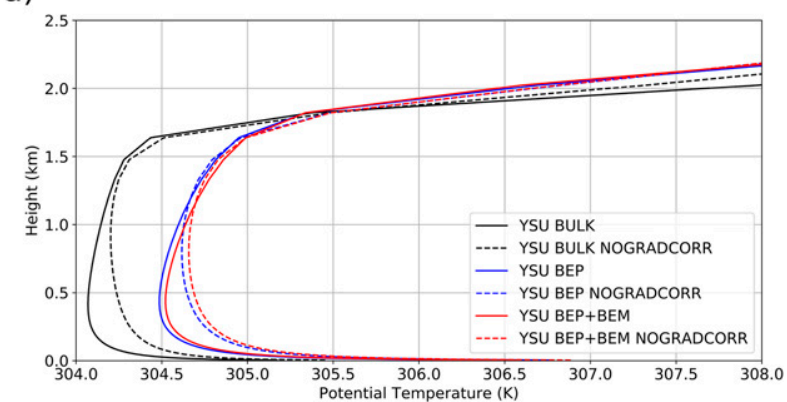

b)

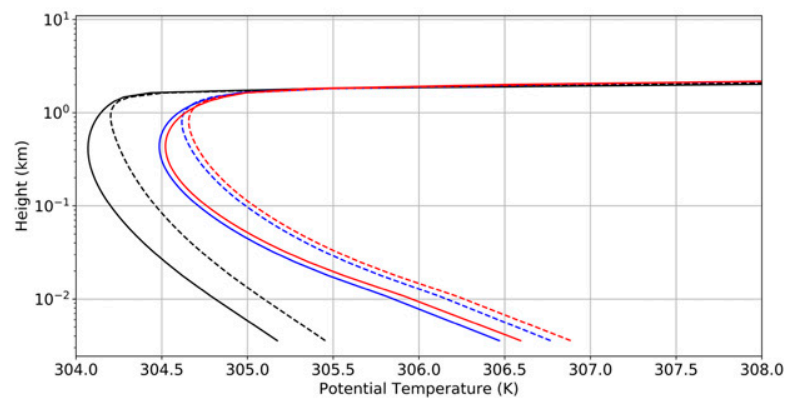

FIG. 8. Vertical profiles of potential temperature $\theta$ averaged over the central patch at $1300 \mathrm{LT}$ in the YSU bulk, BEP, and BEP+BEM simulations with (solid) and without (dashed) the gradient correction term $\gamma_{c}$, depicted with (a) a linear $y$-axis scale over the depth of the PBL and (b) a $\log y$-axis scale showing values near the surface.

turned on during the working day (from 0900 to 1700 LT). This is a reasonable simplifying assumption for the actual A/C system usage in Houston.

\section{b. Observational data}

To evaluate the hierarchy of UCMs in the three PBL parameterizations, a set of observations in an urban environment is necessary. Houston has a network of air quality monitoring sites (continuous ambient monitoring stations) run by the Texas Commission on Environmental Quality (TCEQ). The air monitoring supports the U.S. Environmental Protection Agency's Compliance Assurance Monitoring program. These stations are mostly near the ground; however, a few towers also exist. Most stations monitor air quality (ozone, nitrogen oxides, carbon monoxide, particulate matter, and volatile organic compound concentrations); however, some of these stations also take meteorological measurements. The meteorological parameters that are measured by most stations are wind speed, wind direction, standard deviation of the wind direction, and air temperature. Most stations do not measure the dewpoint, therefore that parameter is not used in the evaluation. The meteorological measurements are saved by TCEQ as hourly averages. The list of stations used, each location and altitude above ground level, 
a)

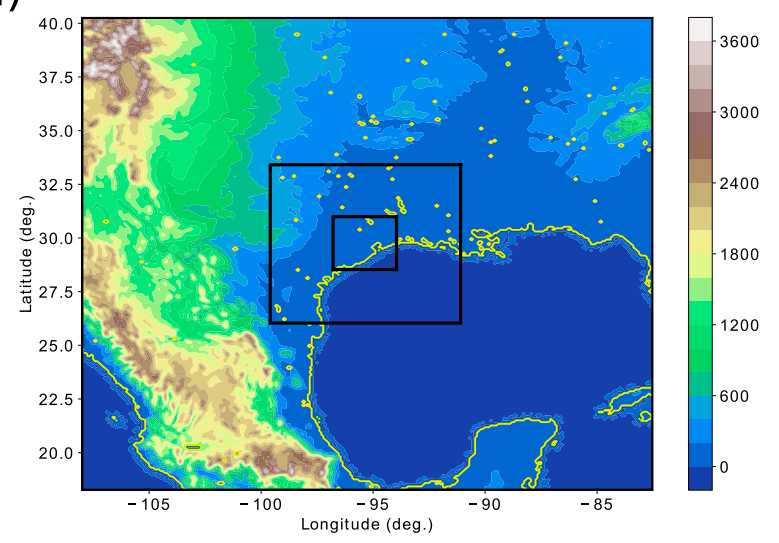

b)

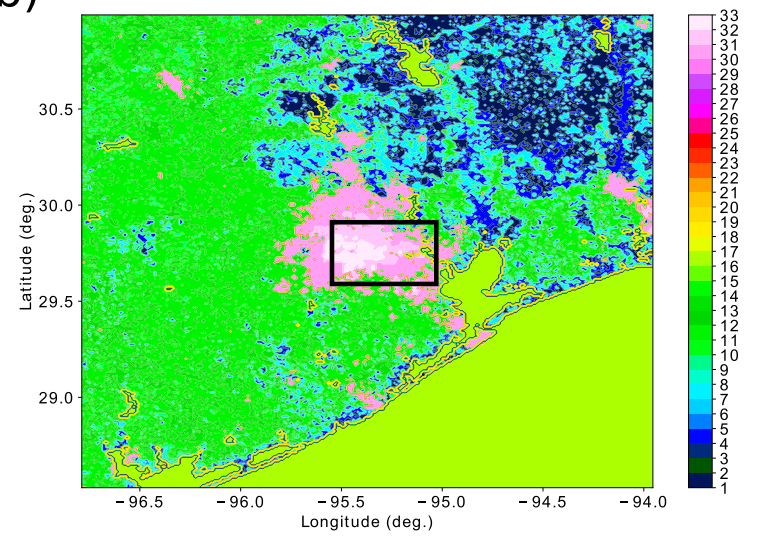

FIG. 9. (a) The WRF Model's nested domains (outlined boxes) and terrain height $(\mathrm{m})$ of domain $1(9 \mathrm{~km})$ as filled contours, and (b) land-use index on the innermost domain 3 . The grid spacings of the outer, middle, and inner domains are 9,3 , and $1 \mathrm{~km}$, respectively. In (b), the land-use indices of 31,32 , and 33 are LIR, HIR, and COI, respectively. Outside the urban area, the land-use indices are mainly croplands and forests. The box outlined in (b) denotes the smaller region over downtown Houston that is plotted in Fig. 10, below.

distance from the approximate center of Houston, urban class, and urban fraction are shown in Table 3. The monitors are $5-18 \mathrm{~m}$ above ground level. Of the seven stations, three are in the LIR urban class and two each are in the HIR and COI urban classes. While seven stations are not sufficient to evaluate all details of the WRF Model simulations in Houston, we feel they are sufficient for the purposes of this study demonstrating the potential usefulness of the YSU PBL parameterization with BEP and BEP+BEM. As discussed by Meier et al. (2017), crowdsourcing of air temperature data from multiple NetAtmo stations can yield important details of the spatial and temporal variability in the urban environment. Future urban modeling studies with the modified YSU scheme with BEP and BEP+BEM could benefit from these observational data.
In Fig. 10a, the WRF Model's urban fraction is shown with the locations of the TCEQ stations used in the study. The stations span a wide range of urban fractions from 0.3 to 1.0. In Fig. 10b, the same stations are plotted with the average building height weighted by building plan area from the NUDAPT dataset (gridded to domain 3 with $1-\mathrm{km}$ grid spacing). The TCEQ stations are located in regions of resolved building heights weighted by plan area of approximately $0-16 \mathrm{~m}$.

\section{c. Results}

In Fig. 11, the 10-m winds are shown at 0600 UTC $(0100 \mathrm{LT}) 6$ October $(t=30 \mathrm{~h})$ and $1800 \mathrm{UTC}(1300 \mathrm{LT})$ 6 October $(t=42 \mathrm{~h})$. At night (Fig. 11a) in all simulations, the built-up area reduces the winds significantly. The land breeze (Tucker et al. 2006) is evident in Houston; the winds blow offshore toward the warmer ocean with a northerly component. The bulk simulations have stronger winds on the northeastern side of Houston than the BEP or BEP+BEM simulations (across all PBL parameterizations, and particularly pronounced in the MYJ and YSU schemes). Among all PBL parameterizations, the BEP and BEP+BEM simulations have weak northerly winds (generally between 0 and $1 \mathrm{~m} \mathrm{~s}^{-1}$ ) in downtown Houston while the bulk simulations have stronger easterly winds. During the day (Fig. 11b), the 10-m winds are more turbulent in all simulations due to the PBL convection. A sea breeze is superimposed on the flow with easterly winds toward Houston. The wind directions are more variable in the $\mathrm{BEP}$ and $\mathrm{BEP}+\mathrm{BEM}$ simulations relative to the bulk simulations, due to the more heterogeneous BEP and BEP+BEM surface momentum forcing. In each simulation, the winds are strongest in the eastern part of Houston (upwind side) and weaker on the western side. The YSU and MYJ simulated winds are stronger than the BOU simulated winds with both BEP and BEP+BEM.

In Figs. 12 and 13, we show the 2-m temperature and sensible heat flux at 0600 UTC (0100 LT) 6 October and 1800 UTC (1300 LT) 6 October, respectively. At night (Fig. 12a), the bulk simulation has a very strong UHI effect, with temperatures approximately $5 \mathrm{~K}$ higher than in the near environment. The BEP+BEM simulations have a stronger UHI effect at this time than the BEP simulations by approximately $2 \mathrm{~K}$. The significant nocturnal UHI effect in all simulations is consistent with the energetic basis described by Oke (1982). Across the PBL parameterizations, there are not significant differences in the nighttime UHI effect, indicating that the surface forcing is dominant, and the influence of stored heat is distributed over a shallower layer due to the stable nighttime boundary layer. Although a surface energy budget would be needed to understand the roles of all terms in the temperature tendency there, the UHI 
TABLE 1. Modified IGBP MODIS Noah land-use indices and descriptions.

\begin{tabular}{cc}
\hline \hline Land-use index & Land-use description \\
\hline 1 & Evergreen needleleaf forest \\
2 & Evergreen broadleaf forest \\
3 & Deciduous needleleaf forest \\
4 & Deciduous broadleaf forest \\
5 & Mixed forests \\
6 & Closed shrublands \\
7 & Open shrublands \\
8 & Woody savannas \\
9 & Savannas \\
10 & Grasslands \\
11 & Permanent wetlands \\
12 & Croplands \\
13 & Urban and built-up \\
14 & Cropland/natural vegetation mosaic \\
15 & Barren or sparsely vegetated \\
16 & Water \\
17 & Wooded tundra \\
18 & Mixed tundra \\
19 & Barren tundra \\
20 & Low-intensity residential \\
31 & High-intensity residential \\
32 & Industrial or commercial \\
33 &
\end{tabular}

effects can often largely be explained by the dominant term of the surface sensible heat fluxes (Arya 2001). The surface sensible heat fluxes are shown in Fig. 12b. The bulk simulations have stronger sensible heat fluxes on the northeastern part of Houston, where the stronger winds impinge on the city. The BEP+BEM simulations have the strongest fluxes in the HIR and COI regions, while the BEP simulations do not have significantly higher fluxes than in the rural environment. There are not significant differences in the surface fluxes among the different PBL parameterizations. The higher simulated temperatures in BEP $+\mathrm{BEM}$ in comparison with $\mathrm{BEP}$ are due to energy exchanges from the interiors of buildings to the environment. Waste heat from $\mathrm{A} / \mathrm{C}$ systems is the dominant component of this energy (transportation waste heat was not modeled in this study). Average waste heat from $\mathrm{A} / \mathrm{C}$ systems is approximately $20 \mathrm{~W} \mathrm{~m}^{-2}$ in Houston in these simulations. This value is broadly consistent with other studies (Chow et al. 2014; Sailor et al. 2015; Salamanca et al. 2014).

During the day (Fig. 13a), more variations in 2-m temperature are seen among the different PBL parameterizations. For the bulk scheme, the YSU simulation has a weaker UHI effect than the MYJ or BOU simulations (by approximately $1 \mathrm{~K}$ ). The BEP and BEP+BEM warm anomalies are mostly confined to the HIR and COI regions. The anomalies are highest in the BOU simulations, followed by the YSU simulations, followed by the MYJ simulations. The YSU UHI effect does not vary as much with the different UCMs as the MYJ or BOU UHI effect. In each PBL parameterization, the high fidelity BEP and BEP+BEM simulations have intricate structures in sensible heat flux (Fig. 13b) due to the improved representation of the complex urban morphology. During the day with stronger vertical mixing, mixing differences among the PBL parameterizations (cf. Fig. 6) are contributing to the differences in the UHI effects in conjunction with the surface forcing.

While many simulations would be needed in a variety of different conditions in order to fully evaluate the performance of each of the nine simulations, here we undertake an evaluation for the selected case study. We evaluate each of the nine simulations against the TCEQ observations. The TCEQ observations are saved as hourly averages and are valid at the midpoint of each hour. Each hour, six time levels of model output (the 10min fields) are averaged to allow them to be compared with the TCEQ observations at the same time. The simulated values are interpolated to the observation locations using inverse-distance weighting on the nearest eight model grid points. Four model grid points are used at the diagnosed level (either 2 or $10 \mathrm{~m}$ ) and four model grid points are used at the WRF first model level at approximately $24 \mathrm{~m}$. Vertical interpolation is necessary (in addition to horizontal interpolation) because of the range of TCEQ sensor heights (Table 3). In evaluating a mesoscale model simulation against point observations in an urban environment, it is important to briefly discuss representativeness error. The mesoscale model simulations using 1-km horizontal grid spacings can resolve features of approximately 6 or $7 \mathrm{~km}$ or larger reasonably well. On the other hand, the observations represent a broader range of atmospheric motion in the PBL, including turbulent motion from eddies much smaller than $6-7 \mathrm{~km}$. While we have chosen to do pointbased verification of the model simulations, it is important to understand that this representativeness error is part of the actual errors that are computed. We assume that this representativeness error is not biased toward any one particular simulation. Additionally, the hourly averaging of the TCEQ observations partially ameliorates this issue, effectively filtering the smaller scale and higher frequency turbulence.

The time series are shown at C1052 (COI station) in Fig. 14; at C1 (HIR station) in Fig. 15; and at C243 (LIR station) in Fig. 16. At C1052, for PBL parameterizations, the BEP and BEP+BEM simulations have more accurate wind speeds than the bulk simulations from $1900 \mathrm{LT}$ 5 October to 0100 LT 6 October. From 0100 to 1300 LT 6 October, all simulations have positive biases around $1-2 \mathrm{~m} \mathrm{~s}^{-1}$. The wind direction at C1052 is predicted 
TABLE 2. Parameters for BEP and BEP+BEM. The UCM in which the parameter is applied is given in the second column, and the values of the parameter for the LIR, HIR, and COI urban classes are given in columns 3-5.

\begin{tabular}{|c|c|c|c|c|}
\hline Parameter & $\mathrm{BEP}$, or $\mathrm{BEP}+\mathrm{BEM}$ & LIR & HIR & COI \\
\hline Roof/wall heat capacity $\left(\mathrm{J} \mathrm{m}^{-3} \mathrm{~K}^{-1}\right)$ & $\mathrm{BEP} ; \mathrm{BEP}+\mathrm{BEM}$ & $1.32 \times 10^{6}$ & $1.32 \times 10^{6}$ & $1.32 \times 10^{6}$ \\
\hline Ground heat capacity $\left(\mathrm{J} \mathrm{m}^{-3} \mathrm{~K}^{-1}\right)$ & $\mathrm{BEP} ; \mathrm{BEP}+\mathrm{BEM}$ & $1.4 \times 10^{6}$ & $1.4 \times 10^{6}$ & $1.4 \times 10^{6}$ \\
\hline $\begin{array}{l}\text { Roof/wall thermal conductivity } \\
\qquad\left(\mathrm{J} \mathrm{m}^{-1} \mathrm{~s}^{-1} \mathrm{~K}^{-1}\right)\end{array}$ & $\mathrm{BEP} ; \mathrm{BEP}+\mathrm{BEM}$ & 0.695 & 0.695 & 0.695 \\
\hline $\begin{array}{l}\text { Road thermal conductivity } \\
\qquad\left(\mathrm{J} \mathrm{m}^{-1} \mathrm{~s}^{-1} \mathrm{~K}^{-1}\right)\end{array}$ & $\mathrm{BEP} ; \mathrm{BEP}+\mathrm{BEM}$ & 0.4004 & 0.4004 & 0.4004 \\
\hline Roof/wall surface albedo & $\mathrm{BEP} ; \mathrm{BEP}+\mathrm{BEM}$ & 0.20 & 0.20 & 0.20 \\
\hline Road surface albedo & $\mathrm{BEP} ; \mathrm{BEP}+\mathrm{BEM}$ & 0.15 & 0.15 & 0.15 \\
\hline Roof/wall surface emissivity & $\mathrm{BEP} ; \mathrm{BEP}+\mathrm{BEM}$ & 0.90 & 0.90 & 0.90 \\
\hline Road surface emissivity & $\mathrm{BEP} ; \mathrm{BEP}+\mathrm{BEM}$ & 0.95 & 0.95 & 0.95 \\
\hline $\begin{array}{l}\text { Roof/road momentum roughness } \\
\text { length }(\mathrm{m})\end{array}$ & $\mathrm{BEP} ; \mathrm{BEP}+\mathrm{BEM}$ & 0.01 & 0.01 & 0.01 \\
\hline Wall momentum roughness length $(\mathrm{m})$ & $\mathrm{BEP} ; \mathrm{BEP}+\mathrm{BEM}$ & 0.0001 & 0.0001 & 0.0001 \\
\hline $\mathrm{A} / \mathrm{C}$ coefficient of performance & $\mathrm{BEP}+\mathrm{BEM}$ & 3.5 & 3.5 & 3.5 \\
\hline Window coverage area & $\mathrm{BEP}+\mathrm{BEM}$ & 0.20 & 0.20 & 0.20 \\
\hline Thermal efficiency of heat exchanger & $\mathrm{BEP}+\mathrm{BEM}$ & 0.75 & 0.75 & 0.75 \\
\hline $\begin{array}{l}\text { Fraction of buildings installed with } \mathrm{A} / \mathrm{C} \\
\text { systems }\end{array}$ & $\mathrm{BEP}+\mathrm{BEM}$ & 1.0 & 1.0 & 1.0 \\
\hline Fraction of cooled floor area in buildings & $\mathrm{BEP}+\mathrm{BEM}$ & 1.0 & 1.0 & 1.0 \\
\hline Target temperature of $\mathrm{A} / \mathrm{C}$ system $(\mathrm{K})$ & $\mathrm{BEP}+\mathrm{BEM}$ & 298 & 298 & 298 \\
\hline Peak occupants per urban floor area & $\mathrm{BEP}+\mathrm{BEM}$ & 0.20 & 0.20 & 0.20 \\
\hline Comfort range of indoor temperature $(\mathrm{K})$ & $\mathrm{BEP}+\mathrm{BEM}$ & 0.5 & 0.5 & 0.5 \\
\hline Target humidity of $\mathrm{A} / \mathrm{C}$ systems $\left(\mathrm{kg} \mathrm{kg}^{-1}\right)$ & $\mathrm{BEP}+\mathrm{BEM}$ & 0.005 & 0.005 & 0.005 \\
\hline $\begin{array}{l}\text { Peak heat generated by equipment } \\
\left(\mathrm{W} \mathrm{m}^{-2}\right)\end{array}$ & $\mathrm{BEP}+\mathrm{BEM}$ & 16 & 20 & 36 \\
\hline
\end{tabular}

reasonably well by each simulation, and the nighttime land breeze (northerly turning of the winds) and daytime sea breeze (easterly turning of the winds) are evident. Larger wind direction errors exist at night when the winds in Houston are lighter. The appearance of large variability at night in the simulations is not real but rather a result of the plotting convention when the wind rotates from a positive direction near zero to under $360^{\circ}$. For all PBL parameterizations the BEP and BEP + BEM wind directions are closer to the TCEQ observations at night from 0100 to 0700 LT 6 October, with a more northerly direction around $20^{\circ}$. Examining the 2-m temperature (middle panel of Fig. 14) from evening in Houston on 5 October to early morning on 6 October, the BEP simulations (across all PBL parameterizations) match the observed temperature most closely. The added anthropogenic heat from BEM produces a slight positive bias in the temperature in comparison to the observations, while the bulk simulations are significantly too warm. In the daytime (from $0700 \mathrm{LT}$ to $1900 \mathrm{LT}$ 6 October), there is less variability among the nine simulations in the temperature, and the more sophisticated UCMs of BEP and BEP+BEM perform better than the bulk scheme. The YSU simulations have mixing ratios that are $1 \mathrm{~g} \mathrm{~kg}^{-1}$ lower than the others in the night and early morning from $0200 \mathrm{LT}$ to $0800 \mathrm{LT} 6$ October $(t=30$ $36 \mathrm{~h})$. The nighttime PBL height reductions from 1900 LT 5 October to 0100 LT 6 October $(t=24-30 \mathrm{~h})$ happen faster in the BEP and BEP+BEM simulations than the bulk simulations. While the exact reason for this is not known, one possibility is that the stronger nocturnal UHI effects in the bulk simulations (Fig. 12a) lead to

TABLE 3. TCEQ air monitoring sites used in this study. The site identifier (ID), latitude, longitude, sampling height, and urban class based upon the WRF Model's land-use category are shown. The " $C$ " in the ID stands for continuous ambient monitoring station.

\begin{tabular}{lccrc}
\hline \hline ID & Lat & Lon & Sampling height $(\mathrm{m})$ & Urban class \\
\hline C1 & 29.767778 & -95.220556 & 9.1 & HIR \\
C169 & 29.706111 & -95.261111 & 5.3 & LIR \\
C243 & 29.672000 & -95.064700 & 18.0 & LIR \\
C409 & 29.623889 & -95.474167 & 6.7 & HIR \\
C1036 & 29.776100 & -95.105100 & 13.5 & LIR \\
C1052 & 29.814530 & -95.387690 & 13.0 & COI \\
C1066 & 29.721600 & -95.492650 & COI \\
\hline
\end{tabular}


a)

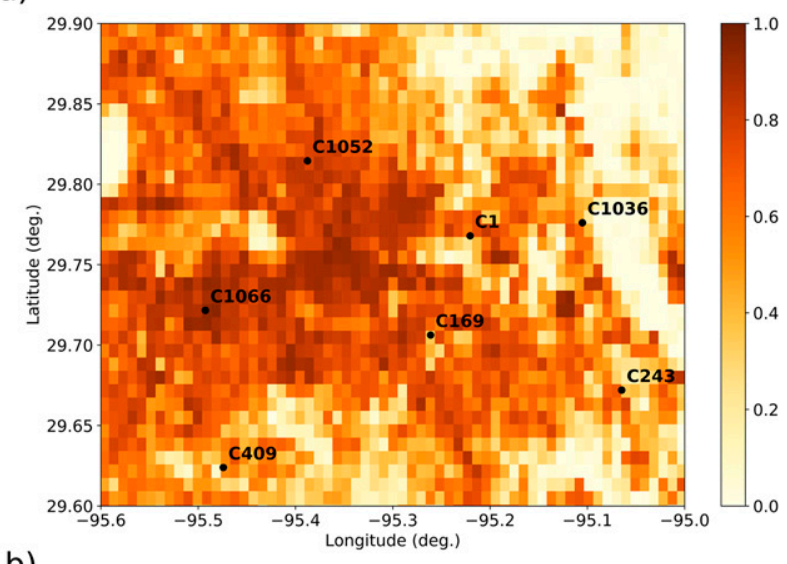

b)

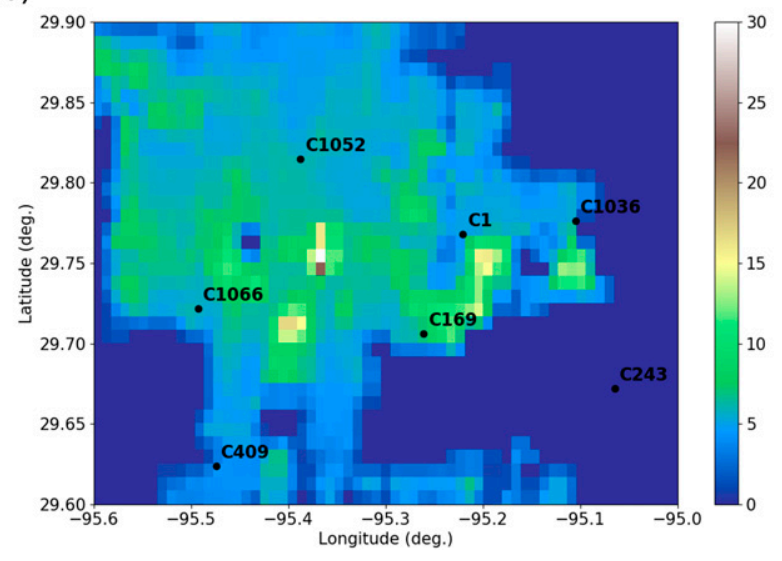

FIG. 10. The WRF Model's urban parameters on domain 3 with horizontal grid spacing of $1 \mathrm{~km}$, showing (a) NUDAPT urban fraction and (b) NUDAPT average building height weighted by building plan area $(\mathrm{m})$. The locations of the TCEQ meteorological surface stations used in the study are marked.

more vertical mixing and a deeper PBL. The daytime PBL growths happen at similar times in each simulation at $0900 \mathrm{LT} 6$ October $(t=39 \mathrm{~h})$. All MYJ simulations have significant high frequency variability in the PBL height in the daytime at the $\mathrm{C} 1052$ location. This is most likely due to high frequency variations in the vertical diffusivity (Fig. 6) as a result of local variations in TKE.

In Fig. 15, the time series are shown at HIR station C1. In the evening (1900 LT 5 October-0100 LT 6 October), the $\mathrm{BEP}$ and $\mathrm{BEP}+\mathrm{BEM}$ simulations have lower wind speeds, consistent with the observations among all PBL parameterizations. In the night and early morning (0100-0700 LT 6 October) and afternoon (1300-1900 LT 6 October) the bulk, BEP, and BEP+BEM simulations are closer to each other, but all simulations have a positive bias. Similar to the COI station C1052, the nighttime wind directions are more accurate in the $\mathrm{BEP}$ and $\mathrm{BEP}+\mathrm{BEM}$ simulations among all PBL parameterizations. Overall, this indicates that the BEP and $\mathrm{BEP}+\mathrm{BEM}$ surface wind fields of Fig. 11b are more accurate than the bulk surface wind fields. The nighttime $\mathrm{BEP}+\mathrm{BEM}$ surface temperatures are the most accurate for each PBL parameterization. In the daytime, both the $\mathrm{BEP}$ and BEP+BEM simulations have accurate temperatures. The bulk simulations have significant positive biases at night (approximately $2-4 \mathrm{~K}$ ) and near zero biases in the day. At $\mathrm{C} 1$ and $\mathrm{C} 1052$, all YSU simulations have lower 2-m mixing ratios than the MYJ or BOU simulations (by approximately $1-2 \mathrm{~g} \mathrm{~kg}^{-1}$ ) between 0100 and $0400 \mathrm{LT}$.

In Fig. 16, the time series are shown at LIR station C243. The bulk simulations more closely match the BEP and $\mathrm{BEP}+\mathrm{BEM}$ simulations here. Possible reasons for the similarities are that this station is in a more exposed location (Fig. 10b) and upwind of the city (wind directions are easterly on average). Some differences are attributed to the fact that the bulk simulations assume a constant urban fraction of 1.0, while the BEP and BEP+BEM simulations do not. Interestingly, among all PBL parameterizations, the $\mathrm{BEP}$ and $\mathrm{BEP}+\mathrm{BEM}$ simulations are able to capture the reduction in wind speed from 1900 to 2200 LT 5 October, while the bulk simulations are not. All simulations have a slight positive wind speed bias at night and negative bias in the day. The wind direction is predicted well at this location overall by most of the nine simulations, with the exception of the BOU BEP and BEP+BEM simulations, which are too northerly between 1900 LT 5 October and 0100 LT 6 October. There is more spread in the 2-m temperature at night than in the day. The MYJ and BOU BEP and BEP+BEM simulations have a small positive bias at night and all simulations have negative biases in the day. The bulk simulations perform much better at this LIR station than at the previous HIR and COI stations. While we have not shown the time series plots for C1066, C409, C1036, and C169, the overall results are generally similar. At C1036, all simulations have larger positive biases in the wind speed of approximately $2 \mathrm{~m} \mathrm{~s}^{-1}$ and larger positive biases in temperature at night. The reasons for the poorer comparisons at $\mathrm{C} 1036$ are not known.

We now examine the statistical performance measures for all nine simulations in comparison to all TCEQ station observations during the latter 24 -h period. The statistical evaluation is based on the traditional performance measures of mean error (ME) (or equivalently, the unconditional bias) and root-mean-square error (RMSE) (e.g., Murphy et al. 1989),

$$
\begin{aligned}
\mathrm{ME} & =\bar{M}-\bar{O} \text { and } \\
\mathrm{RMSE} & =\left[\frac{1}{N} \sum_{i=0}^{N}\left(M_{i}-O_{i}\right)^{2}\right]^{1 / 2},
\end{aligned}
$$


a)
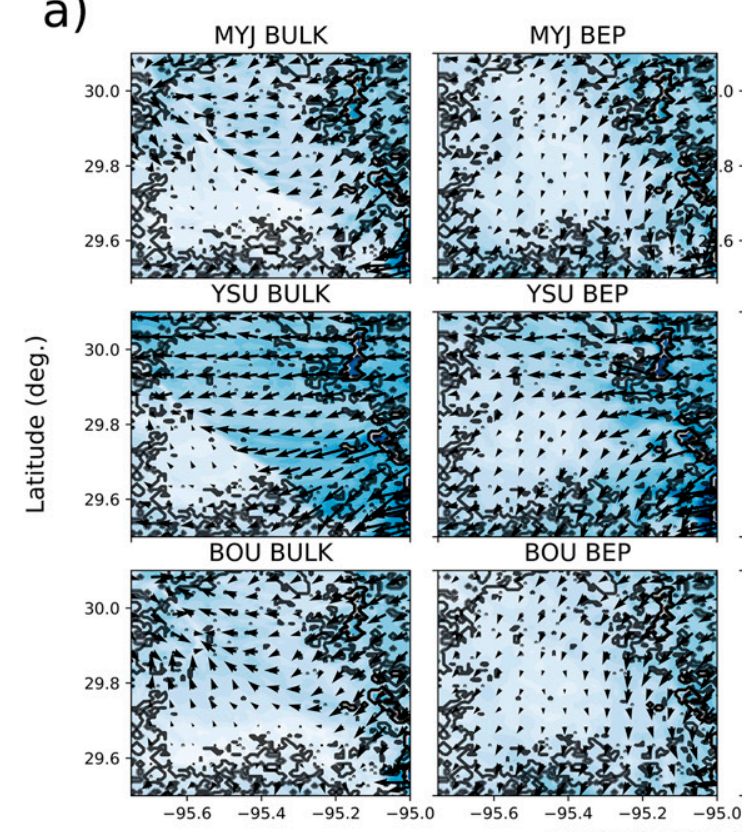

YSU BEP

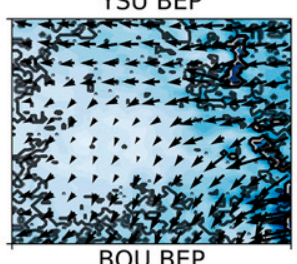

BOU BEP

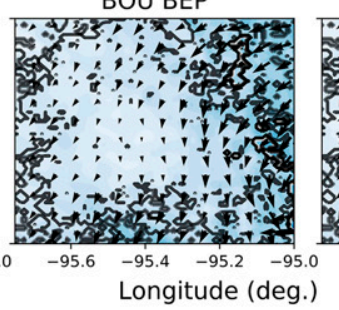

b)

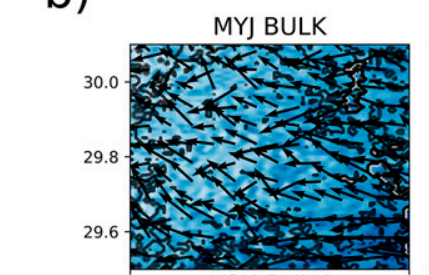

YSU BULK
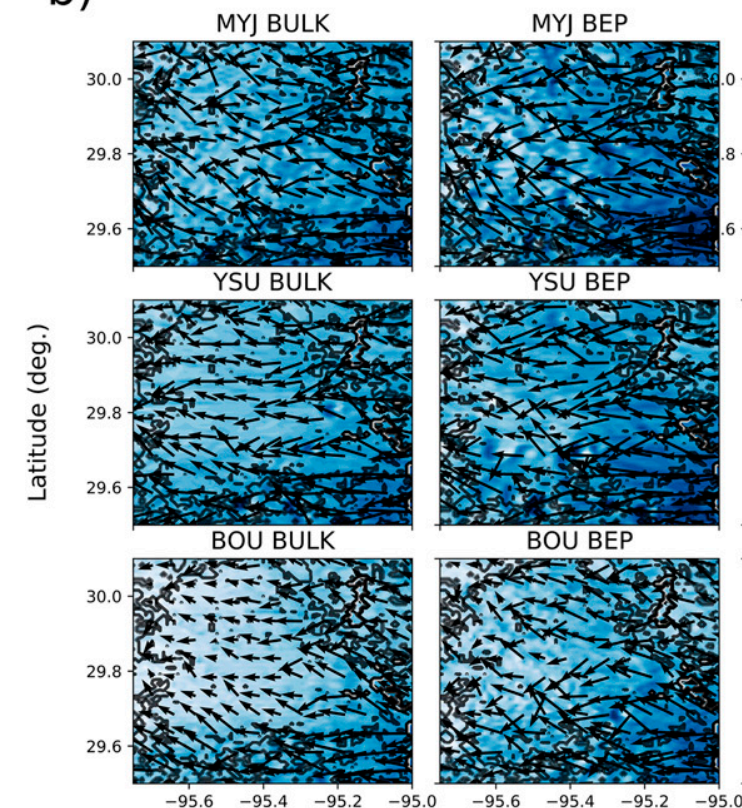

YSU BEP

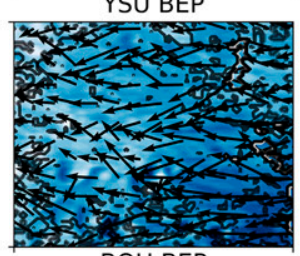

BOU BEP

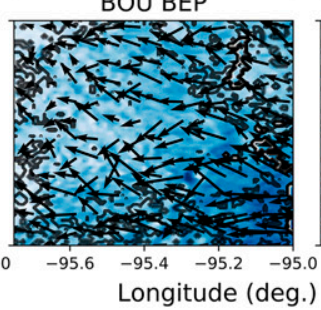

MYJ BEP+BEM

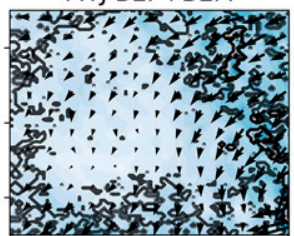

YSU BEP+BEM

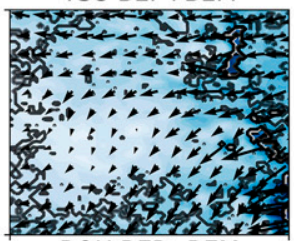

BOU BEP+BEM

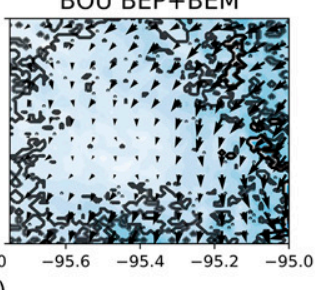

$M Y J] B E P+B E M$

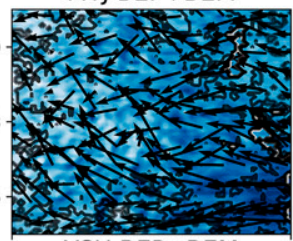

YSU BEP+BEM

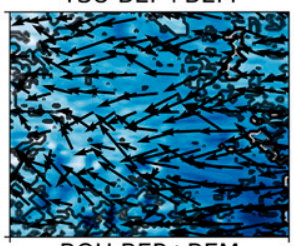

BOU BEP+BEM

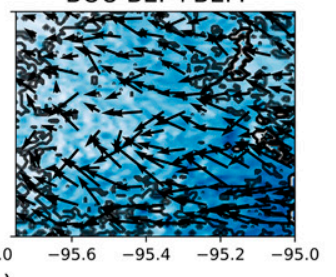

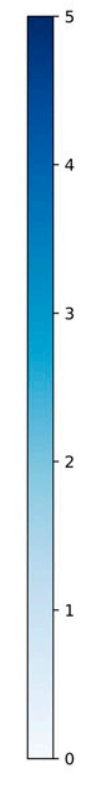

FIG. 11. The WRF Model's simulated 10-m winds $\left(\mathrm{m} \mathrm{s}^{-1}\right.$ ) at (a) $t=30 \mathrm{~h}$ (valid $0600 \mathrm{UTC} / 0100 \mathrm{LT}$ $6 \mathrm{Oct}$ ) and (b) $t=42 \mathrm{~h}$ (valid $1800 \mathrm{UTC} / 1300 \mathrm{LT} 6 \mathrm{Oct}$ ). The outline of the LIR area of Houston is shown by the contour. Vectors are plotted every 6 model grid points.

where $M$ is the model interpolated value (inverse distance weighted) at the TCEQ location and $O$ is the TCEQ observation. Overbars denote the mean value of all model simulations or observations in each of the three groups. For each quantity, the results are stratified by six groups (rows): (i) all $(N=168)$, (ii) day
(1200-0000 UTC/0700-1900 LT; $N=84$ ), (iii) night (0000-1200 UTC/1900-0700 LT; $N=84$ ), (iv) LIR stations $(N=72)$, (v) HIR stations $(N=48)$, and (vi) COI stations $(N=48)$. The number of evaluation points $N$ is the number of hourly comparison points multiplied by the number of TCEQ stations. For example, 
a)
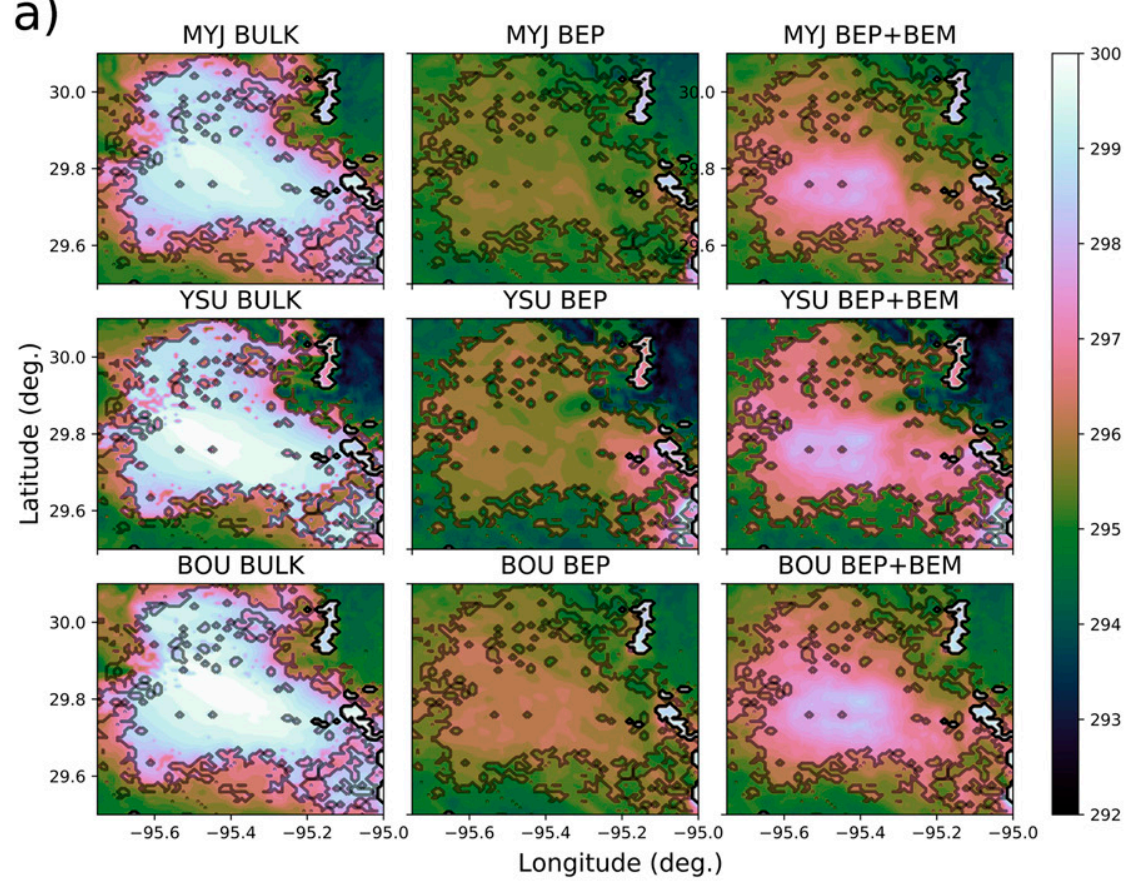

b)
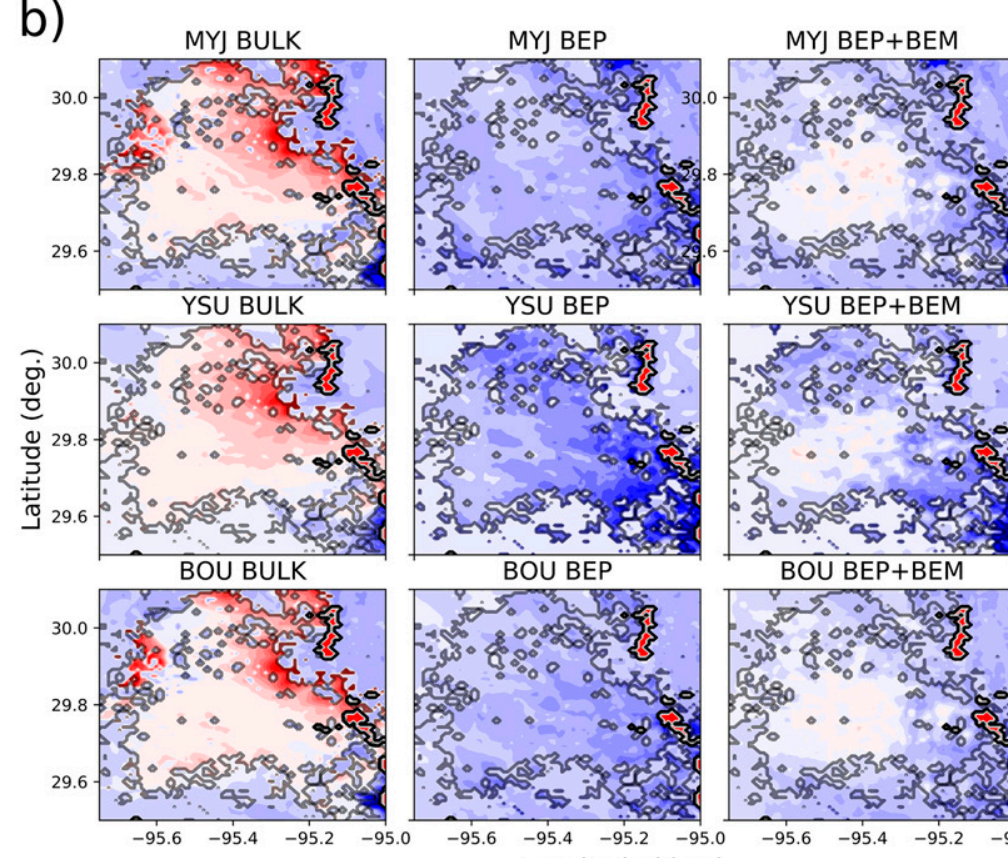

Longitude (deg.)

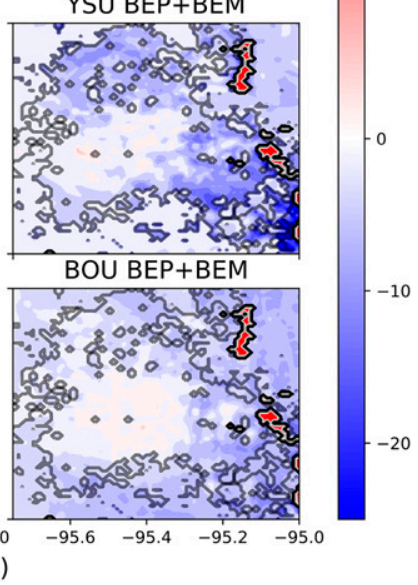

FIG. 12. The WRF Model's simulated near-surface output variables at $t=30 \mathrm{~h}$ (valid 0600 UTC/0100 LT 6 Oct): (a) 2-m temperature (K) and (b) sensible heat flux ( $\mathrm{W} \mathrm{m}^{-2}$ ). The outline of the LIR area of Houston is shown by the contour.

in the "all" group, there are 24 paired points times 7 TCEQ stations.

The statistical evaluation of the $10-\mathrm{m}$ winds is given in Fig. 17. In the all group, the ME is reduced by $0.1-$ $0.2 \mathrm{~m} \mathrm{~s}^{-1}$ in the BEP and BEP+BEM simulations over the bulk simulations for the MYJ, BOU, and YSU PBL parameterizations $(\mathrm{BEP}$ and $\mathrm{BEP}+\mathrm{BEM}$ MEs range from 0.7 to $0.9 \mathrm{~m} \mathrm{~s}^{-1}$ ). Averaging across bulk, BEP, and $\mathrm{BEP}+\mathrm{BEM}$, the BOU simulations have the lowest MEs, followed by MYJ simulations, followed by the YSU 
a)

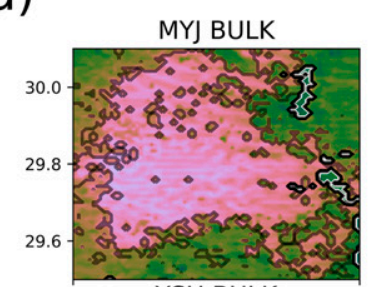

YSU BULK

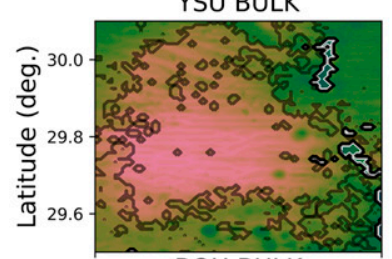

BOU BULK

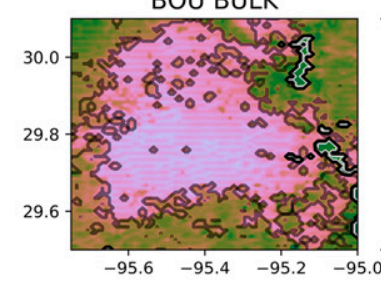

b)
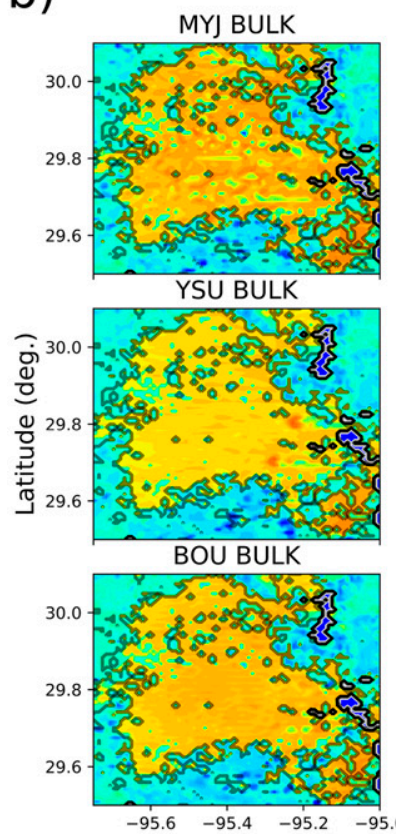

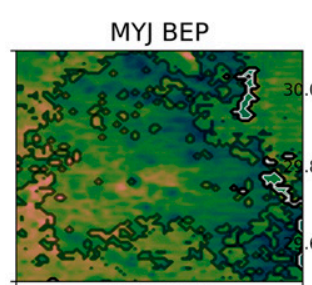

YSU BEP

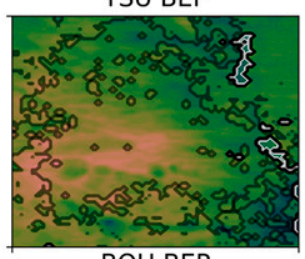

BOU BEP

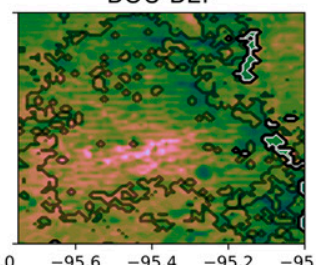

Longitude (deg.)
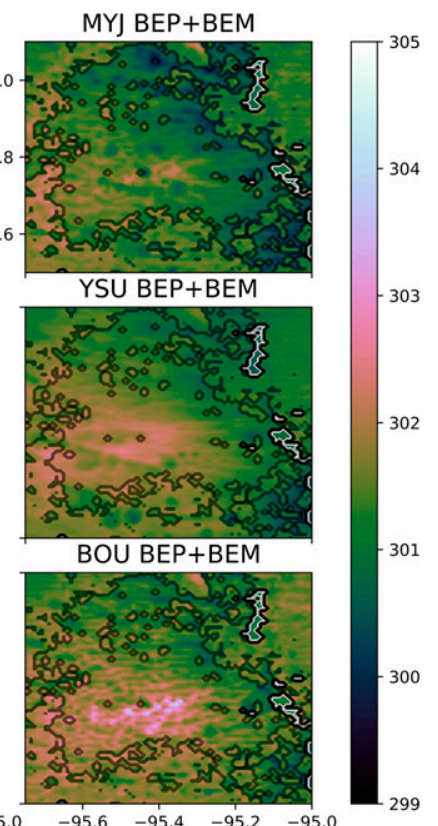

MYJ BEP

MYJ BEP+BEM

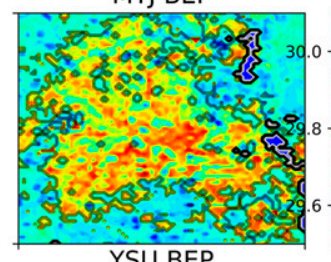

YSU BEP

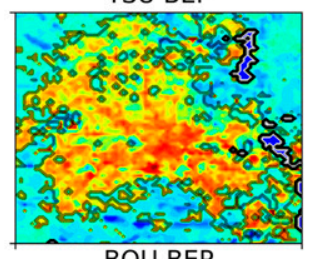

BOU BEP

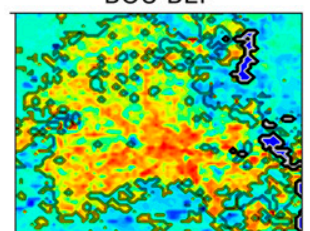

0.050 .

$\begin{array}{llll}-95.6 & -95.4 & -95.2 & -95.0 \\ & \text { Longitude (deg.) }\end{array}$

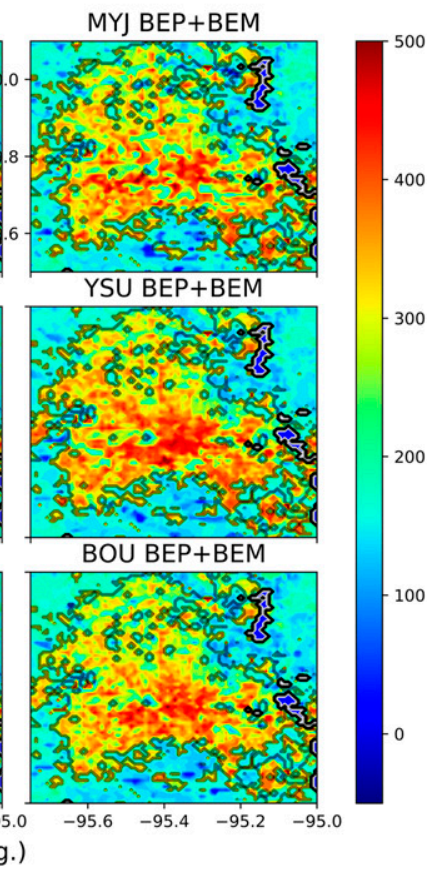

FIG. 13. As in Fig. 12, but at $t=42 \mathrm{~h}$ (valid 1800 UTC/1300 LT 6 Oct).

simulations. Slight reductions in RMSEs are also evident using BEP and BEP+BEM over the bulk scheme in all PBL parameterizations, and RMSEs are approximately $1.3-1.5 \mathrm{~m} \mathrm{~s}^{-1}$. During the day, the bulk simulations have a lower ME than the BEP and BEP+BEM simulations with all PBL parameterizations (particularly pronounced in the BOU bulk simulations). RMSEs range from approximately $1.1-1.2 \mathrm{~m} \mathrm{~s}^{-1}$, and the YSU and MYJ BEP and BEP+BEM simulations have larger RMSEs than the corresponding BOU simulations. At night, significant ME reductions are evident in the BEP and BEP+BEM simulations among all PBL parameterizations. There is also an overall reduction in the RMSEs for each PBL parameterization with the use of 

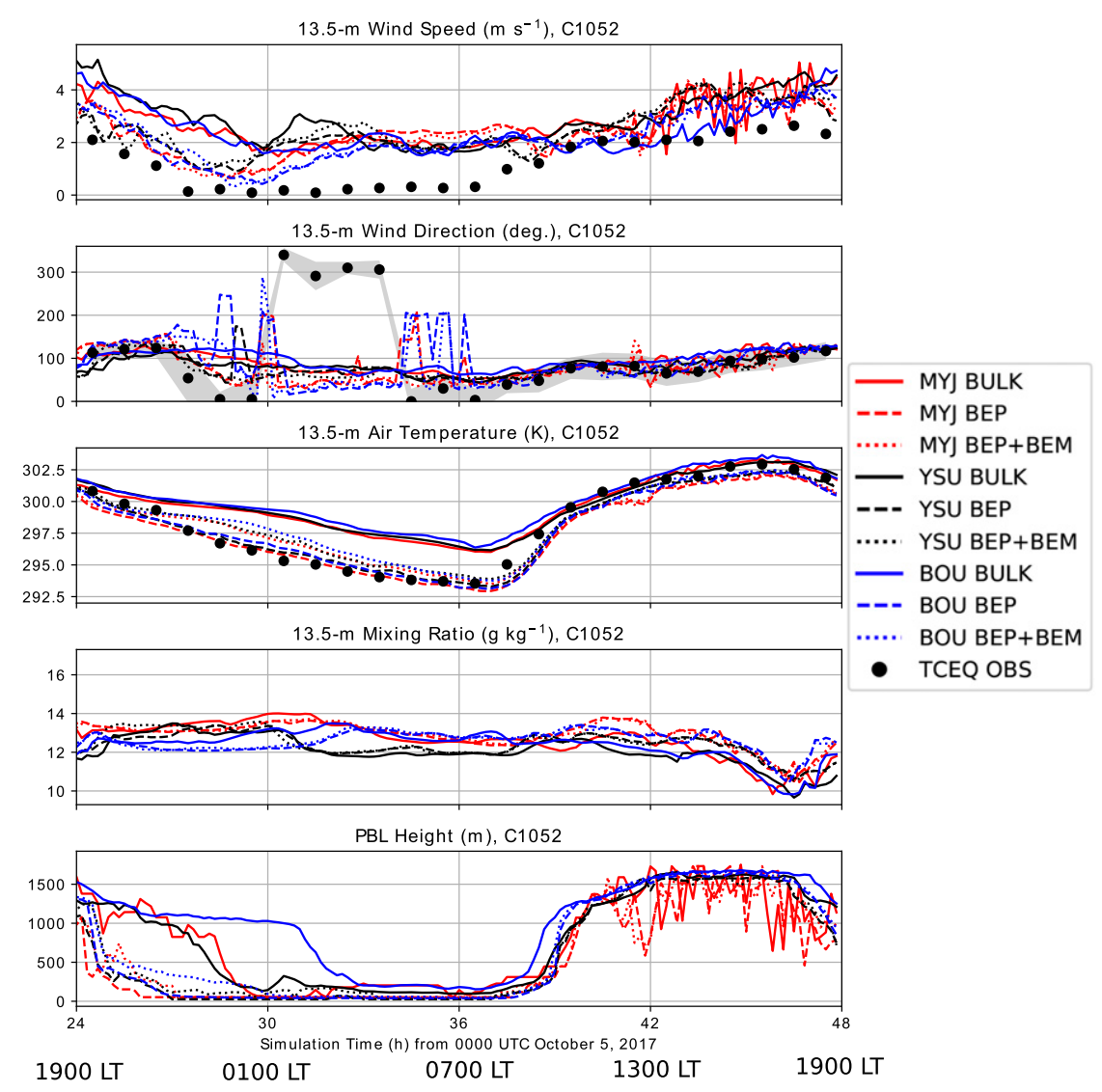

FIG. 14. Time series of the WRF Model's domain 3 and TCEQ observations at COI station C1052. The WRF Model's time series are given at an interval of $10 \mathrm{~min}$, and the TCEQ hourly averaged observations are shown as black dots. Shown are (top) near-surface wind speed, (top middle) wind direction, (middle) air temperature, (bottom middle) mixing ratio, and (bottom) PBL height. In the wind direction plot, the gray shading denotes the observed standard deviation at the TCEQ station. The MYJ simulations are in red, the YSU simulations are in black, and the BOU simulations are in blue.

BEP and BEP +BEM. Stratifying by urban class, relatively minor improvements in the ME and RMSE are evident for each PBL parameterization with BEP and $\mathrm{BEP}+\mathrm{BEM}$ over the bulk scheme.

The 2-m temperature statistical performance measures are given in Fig. 18. In the all group and for each PBL parameterization, BEP and BEP+BEM have MEs closer to zero than the bulk scheme. In particular, the $\mathrm{BEP}+\mathrm{BEM}$ simulations have MEs closest to zero (small negative biases from -0.25 to $-0.05 \mathrm{~K}$ ). The RMSEs with $\mathrm{BEP}$ and $\mathrm{BEP}+\mathrm{BEM}$ are approximately $1.1-1.5 \mathrm{~K}$ and are lower than the $1.8-2.0 \mathrm{~K}$ in the bulk simulations. In the day, the bulk simulations have small negative MEs while the $\mathrm{BEP}$ and $\mathrm{BEP}+\mathrm{BEM}$ simulations have larger negative MEs from -1.4 to $-0.7 \mathrm{~K}$. At night, BEP and $\mathrm{BEP}+\mathrm{BEM}$ have MEs closer to zero than the bulk scheme across all PBL parameterizations (BEP simulations are superior). The bulk simulations have larger positive MEs of approximately $1.8-2.0 \mathrm{~K}$. At night, for each PBL parameterization with BEP and BEP+BEM, the 2-m temperature RMSEs are 1.1-1.4 K. The bulk simulation RMSEs are around 2.1-2.3 K. Stratifying by urban class, the ME is significantly improved with BEP and BEP + BEM in the LIR urban class. In the HIR urban class, the $\mathrm{BEP}+\mathrm{BEM}$ simulations are superior, with small negative MEs. RMSEs are also improved the most in the LIR and HIR urban classes with BEP and BEP+BEM. The combination of the LIR and nighttime results indicate that the large areal extent of a significant UHI anomaly in the bulk simulation (Fig. 12a) is erroneous.

\section{d. Synthesis of results from real-case simulations}

In the study of the real case, the YSU simulations with $\mathrm{BEP}$ and BEP+BEM have similar evolutions as the MYJ and BOU simulations near the surface. This is especially evident at night when higher stability near the ground allows the BEP and BEP+BEM source terms to dominate the state variable evolution. Specifically, the usage of BEP 

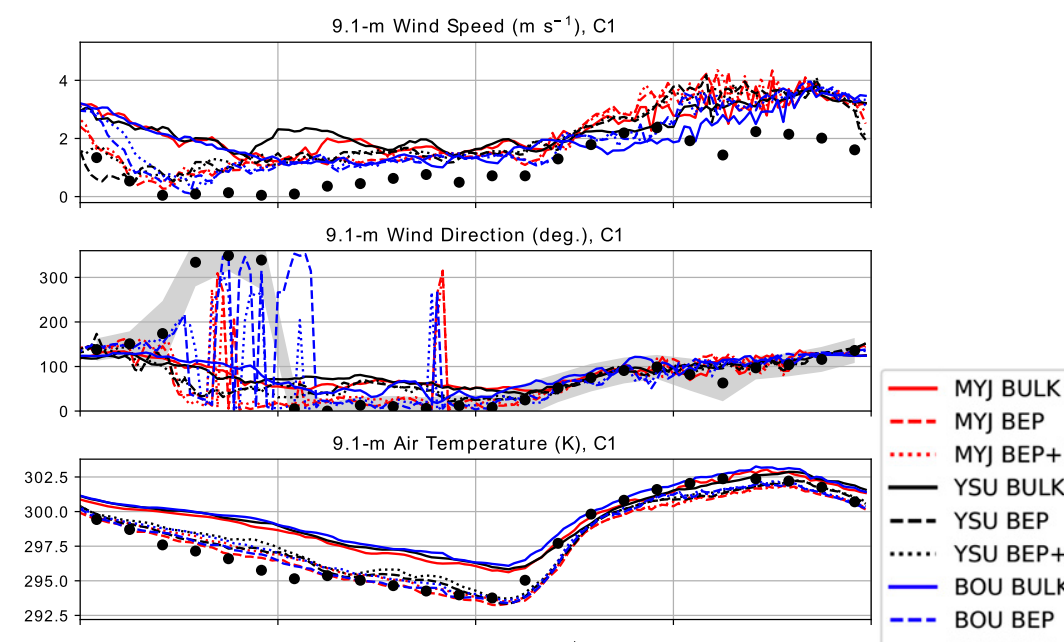

--- MYJ BEP

… MYJ BEP+BEM

- YSU BULK

--- YSU BEP

… YSU BEP+BEM

- BOU BULK

--- BOU BEP

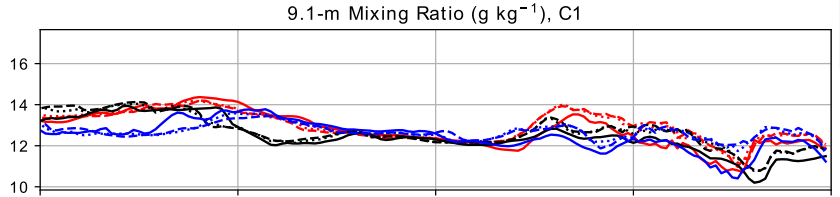

… BOU BEP+BEM

- TCEQ OBS

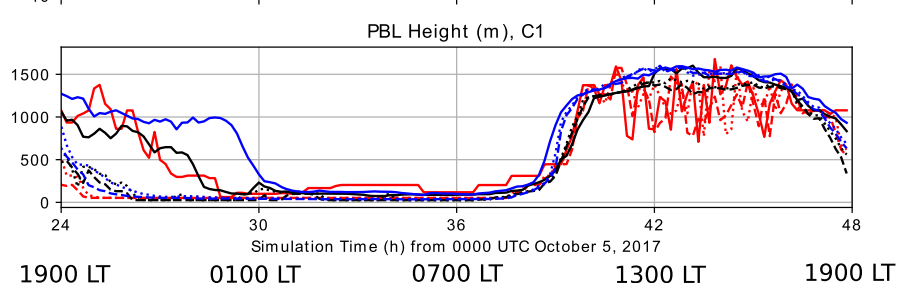

FIG. 15. As in Fig. 14, but for HIR station C1.

and $\mathrm{BEP}+\mathrm{BEM}$ yield improved prediction of nighttime 10-m wind speed, 10-m wind direction, and 2-m temperatures by all PBL parameterizations. In the day, there are more significant differences among the PBL parameterizations as differences in vertical mixing also contribute to the near-surface evolution. Through evaluation with urban near-surface observations in a real-case study, for each PBL parameterization, the usage of BEP and BEP + BEM improves the overall near-surface wind and temperature biases and root-mean-square errors over the simple bulk schemes. The improvements in the temperature biases and root-mean-square errors are more significant than in the winds. We recognize that one real-case study is not sufficient to assess whether any statistically significant biases exist in simulations using the YSU PBL parameterization with $\mathrm{BEP}$ and $\mathrm{BEP}+\mathrm{BEM}$. Future modeling studies over a wide a range of different meteorological conditions will help to clarify the overall performance of the scheme.

\section{Interpretation of results}

The ideal and real simulations demonstrate that BEP and $\mathrm{BEP}+\mathrm{BEM}$ in the YSU PBL parameterization produce results that are qualitatively similar to the TKE-based PBL parameterizations in which the multilayer UCMs have long existed. The newly modified YSU code allows for insight into urban surface and boundary layer processes in a nonlocal closure scheme. We now discuss some reasons for the behaviors by examining details of the BEP and BEP+BEM implementation in each PBL parameterization.

The MYJ and BOU parameterizations use 1.5-order, local closure, with prediction of TKE. In the YSU PBL parameterization, the vertical diffusivity $K$ of heat and momentum is a specified function [a so-called $K$-profile scheme; Eq. (A1) of Hong et al. 2006], and nonlocal effects and entrainment at the top of the PBL are included. The addition of BEP and BEP + BEM is similar in each PBL parameterization in that the $A$ and $B$ components are included as implicit and explicit source terms, respectively, in a general vertical diffusion equation. These source terms force the zonal velocity, meridional velocity, potential temperature, and mixing ratio. The major differences are within the TKE prognostic equation and computation of the vertical diffusivity $K$. In the MYJ and BOU PBL parameterizations, BEP and BEP+BEM directly modify the TKE prognostic equation with both a 

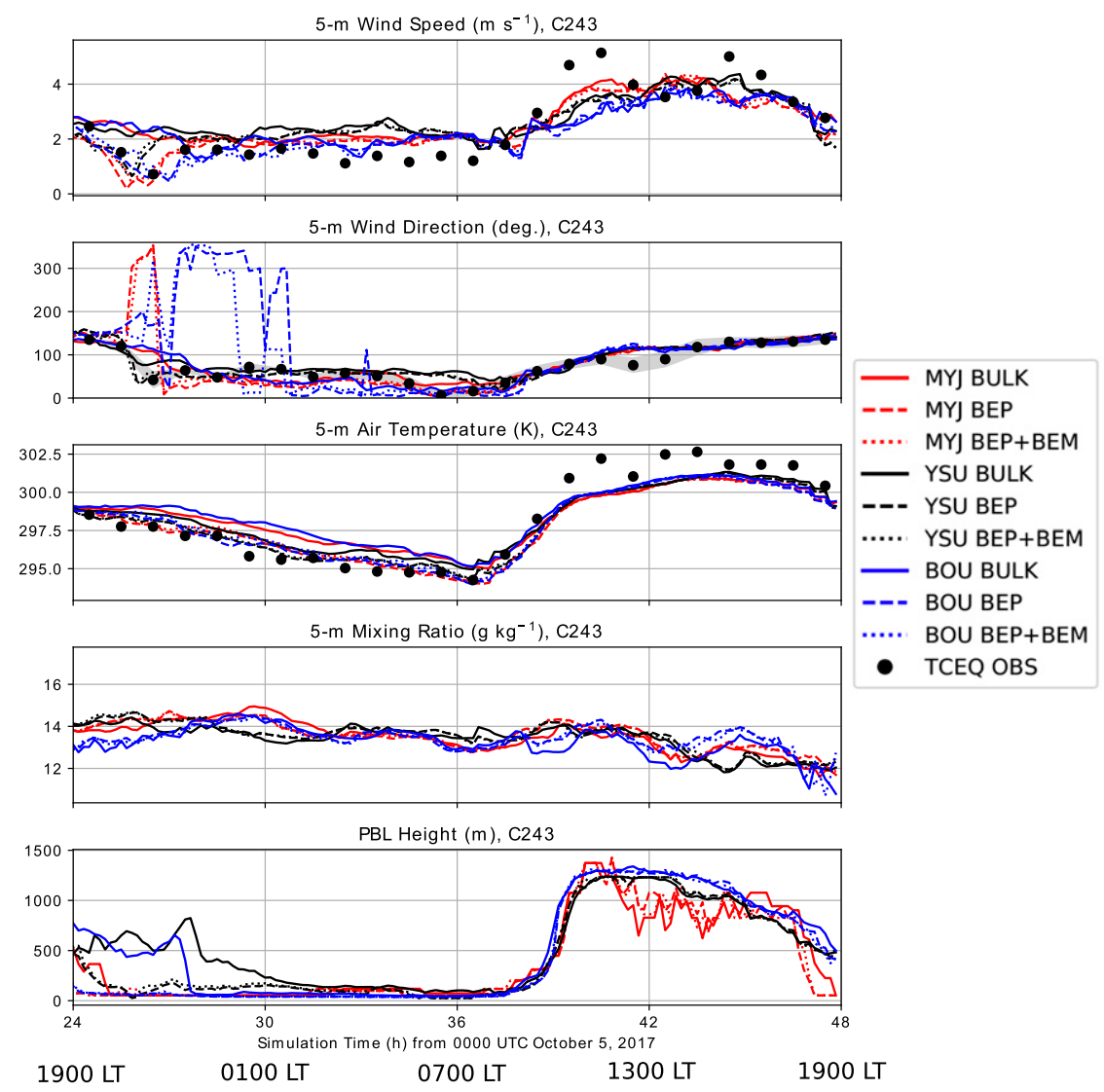

FIG. 16. As in Fig. 14, but for LIR station C243.

source term for how buildings disrupt the airflow, and a reduction of the turbulence length scales, which increases the TKE dissipation term (Martilli et al. 2002). The modified TKE and turbulence length scales lead directly to local changes in the vertical diffusivities in the MYJ and BOU PBL parameterizations, modifying the local vertical mixing. In the implementation of BEP and BEP+BEM in the YSU PBL parameterization, the amplitude of the $K$ profile is directly modified by the surface fluxes, which are in turn modified by the BEP and BEP+BEM surface forcing. However, there are no local modifications to the vertical diffusivities in the YSU scheme, as there are in the MYJ and BOU schemes. Finally, in the YSU PBL scheme implementation, BEP and BEP+BEM modify the gradient adjustment term for nonlocal mixing through the surface fluxes.

Considering the significant differences between how vertical mixing is treated in the nonlocal and local PBL closure schemes, it is interesting that the differences among the PBL parameterizations for a given UCM are relatively minor in the cases we have studied. This suggests that the $\mathrm{BEP}$ and $\mathrm{BEP}+\mathrm{BEM}$ source term forcings are more dominant in each scheme than the vertical mixing, particularly at night when vertical mixing is suppressed. Considering the relatively similar results, this leads to the question of why BEP and BEP+BEM would be preferred in one PBL parameterization versus another. For detailed studies of buildings' TKE effects on local vertical mixing, the MYJ or BOU PBL parameterizations are preferred because they explicitly predict TKE. For general urban modeling studies, any of the three PBL parameterizations are sufficient. Another aspect to consider is that certain PBL parameterizations are used for simulations in different geographic areas and times of year based upon known biases (Cohen et al. 2015). Operational forecast centers may have to use one PBL parameterization instead of another to mitigate biases and produce more accurate forecasts, even if the reasons for the biases are not well understood. Therefore, it would be useful to have BEP and BEP + BEM functionality in more PBL parameterizations. On this thread, there is a movement in the modeling community to use physical parameterization suites that include one predetermined PBL parameterization. As an example, the WRF tropical physical parameterization suite currently includes the YSU PBL parameterization. 


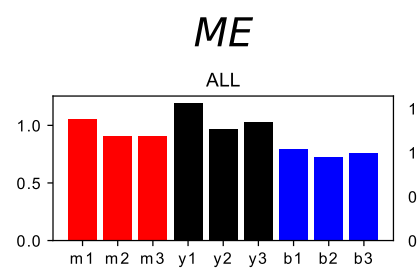

DAY
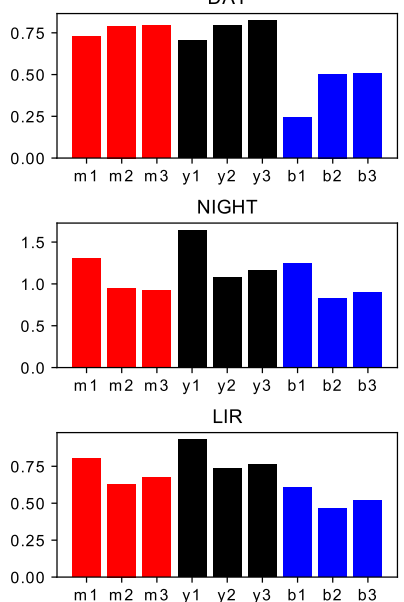

HIR

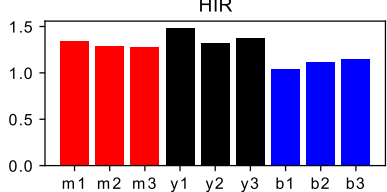

$\mathrm{COI}$
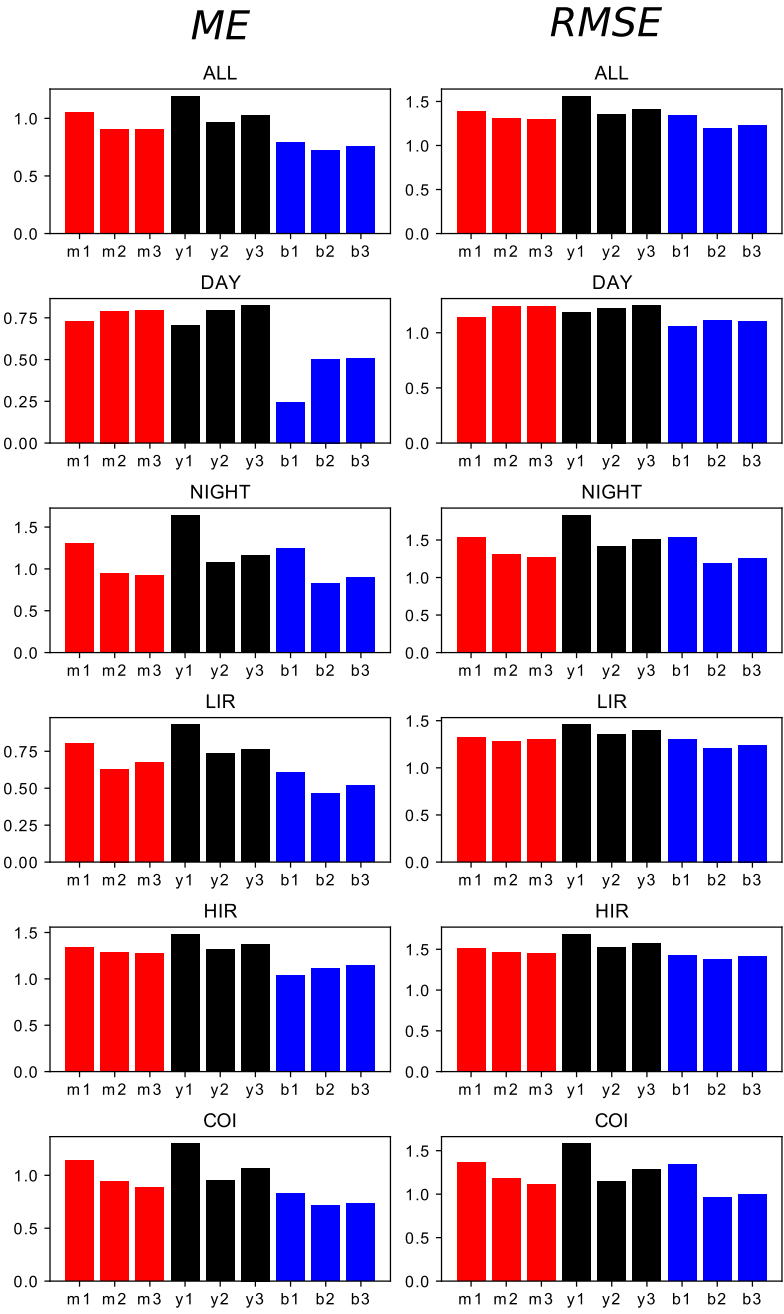

DAY

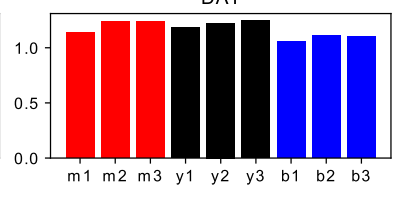

NIGHT

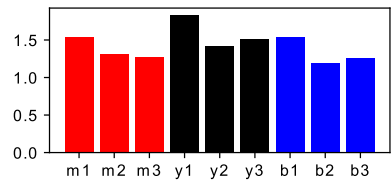

LIR

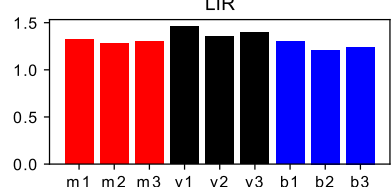

HIR

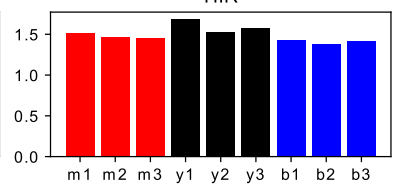

$\mathrm{COI}$

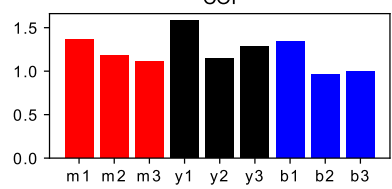

FIG. 17. Verification of simulated $10-\mathrm{m}$ wind speed $\left(\mathrm{m} \mathrm{s}^{-1}\right)$ vs TCEQ observations for different periods of the diurnal cycle and different land-use categories, showing (left) ME and (right) RMSE. The MYJ simulations are red, the YSU simulations are black, and the BOU simulations are blue. The MYJ simulations are MYJ bulk (m1), MYJ BEP (m2), MYJ BEP+BEM (m3). The YSU simulations are: YSU bulk (y1), YSU BEP (y2), and YSU BEP+BEM (y3). The BOU simulations are BOU bulk (b1), BOU BEP (b2), and BOU BEP+BEM (b3).

Considering how BEP represents the building drag much better than the bulk scheme, the addition of BEP to the YSU scheme could be of critical importance for improving urban canopy wind forecasts for landfalling hurricanes.

\section{Conclusions}

$\mathrm{BEP}$ and $\mathrm{BEP}+\mathrm{BEM}$ were added to the YSU PBL parameterization, and the modified YSU PBL scheme was evaluated in ideal and real cases using the WRF Model. The modified scheme was compared to the
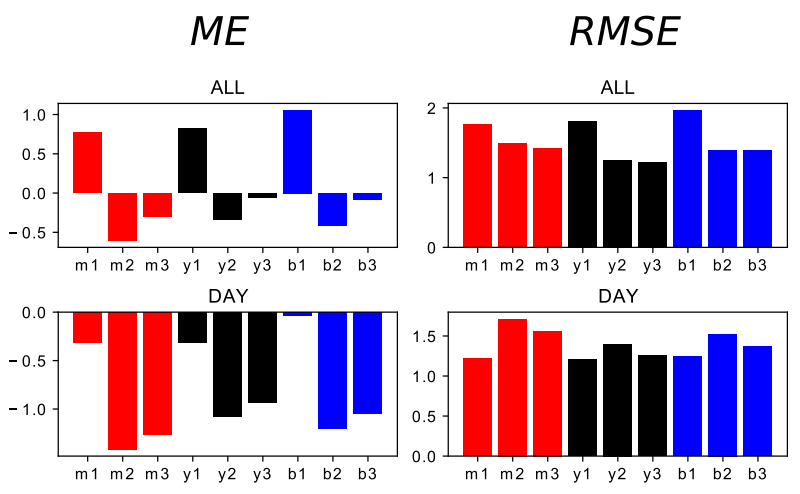

DAY

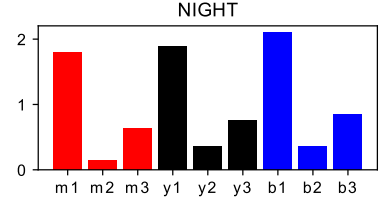

LIR

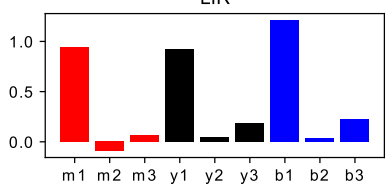

HIR

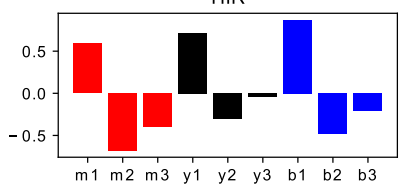

$\mathrm{CO}$
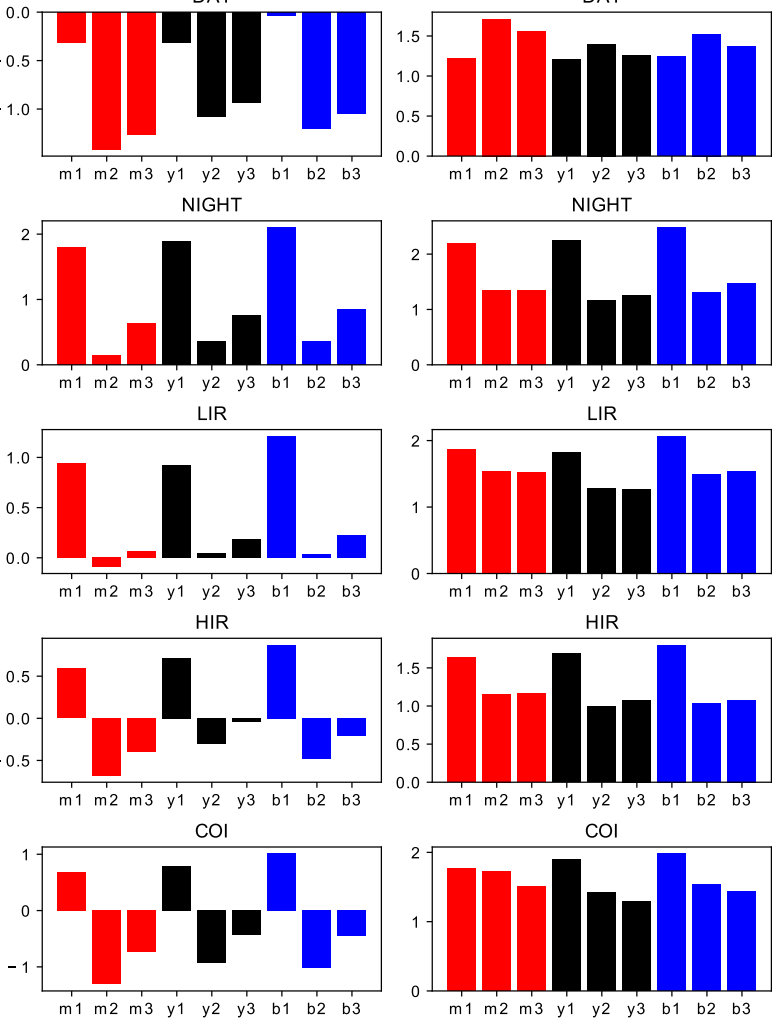

NIGHT

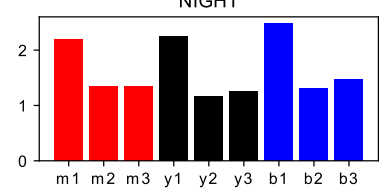

LIR

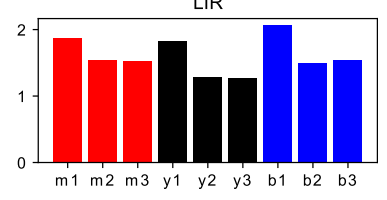

HIR

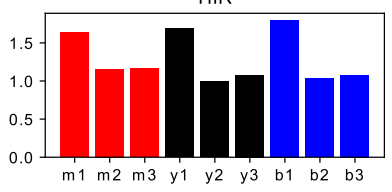

$\mathrm{COI}$

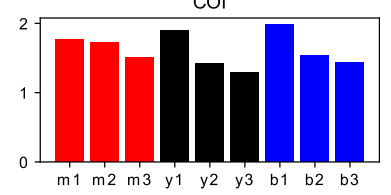

FIG. 18. As in Fig. 17, but for 2-m temperature (K).

two other PBL parameterizations in which BEP and $\mathrm{BEP}+\mathrm{BEM}$ are currently implemented (MYJ and BOU). A key difference between the YSU and MYJ/BOU PBL parameterizations is that YSU uses first-order nonlocal closure, while MYJ and BOU use 1.5-order local closure with TKE prediction. In the MYJ and BOU PBL parameterizations, buildings generate TKE and modify the turbulent length scales and dissipation of TKE, which in turn modifies the vertical diffusivity locally. This effect does not exist in YSU since TKE is not predicted, and the amplitude of the vertical diffusivity is modified through building effects on the surface fluxes only. Overall, we demonstrated that BEP and $\mathrm{BEP}+\mathrm{BEM}$ allow insights into how buildings affect the UCL and PBL in a nonlocal closure parameterization. The additions of these multilayer UCMs to the YSU PBL parameterization should facilitate other real-case studies in different conditions in the future, allowing for further understanding and advancement of the UCMs. 
In the ideal-case study, we demonstrated how BEP and $\mathrm{BEP}+\mathrm{BEM}$ force the near-surface and boundary layer in the YSU PBL parameterization and showed that the behaviors are realistic, or produce results that are sufficiently similar to other well-established schemes of MYJ and BOU. We further demonstrated that BEP and BEP+BEM produce expected behaviors in a realcase study in Houston. At night, when the vertical mixing is small, there were minor differences in the UHI effect among the PBL parameterizations for a given UCM. In the day, larger differences were seen, due to differences in vertical mixing near the surface among the different PBL parameterizations. We quantitatively evaluated the performance of nine simulations using near-surface observations in Houston. Overall, the usage of BEP and BEP+BEM significantly improved the overall near-surface temperature bias, and slightly improved the overall wind speed bias for the three PBL parameterizations over the bulk scheme. The improvements were more significant at night than in the day.

Acknowledgments. This material is based upon work supported by the National Center for Atmospheric Research (NCAR), which is a major facility sponsored by the National Science Foundation under Cooperative Agreement 1852977. Authors Hendricks and Knievel acknowledge the support from the National Science Foundation (NSF) Prediction of and Resilience against Extreme Events (PREEVENTS) grant 1663978, managed by Justin E. Lawrence, and the U. S. Army Test and Evaluation Command (ATEC) through an Interagency Agreement with the NSF. Author Wang acknowledges support from the NCAR Advanced Study Program. The authors thank Hailey Shin, George Bryan, Alberto Martilli, Dave Nolan, and Stephan DeWekker for helpful discussions. This paper was improved by the constructive comments of three anonymous reviewers.

\section{APPENDIX}

\section{Finite-Difference Method for Obtaining Numerical Solutions to Eq. (1)}

The YSU vertical diffusion equation with the BEP and BEP+BEM source terms [Eq. (1)] is solved implicitly following Martilli et al. (2009). First, we let $k$ denote the integer vertical levels in the WRF Model and $k+1 / 2$ denote the half-integer vertical levels (faces). Then, the time level is indexed using $n$. With these indexing notations, the vertically discrete implicit equation is

$$
\begin{aligned}
\frac{C_{k}^{n+1}-C_{k}^{n}}{\Delta t}= & \frac{1}{v_{k} \Delta z_{k} \rho_{k}}\left[\frac{s_{k+1 / 2} \rho_{k+1 / 2} K_{k+1 / 2}}{\Delta z_{k+1 / 2}}\left(C_{k+1}^{n+1}-C_{k}^{n+1}+\Delta z_{k+1 / 2} \alpha_{k+1 / 2}\right)\right] \\
& -\frac{1}{v_{k} \Delta z_{k} \rho_{k}}\left[\frac{s_{k-1 / 2} \rho_{k-1 / 2} K_{k-1 / 2}}{\Delta z_{k-1 / 2}}\left(C_{k}^{n+1}-C_{k-1}^{n+1}+\Delta z_{k-1 / 2} \alpha_{k-1 / 2}\right)\right]+A_{k} C_{k}^{n+1}+B_{k}
\end{aligned}
$$

where $C$ is the solution variable, $\alpha=-\gamma_{c}-\left(\overline{w^{\prime} c^{\prime}}\right)_{h}(z / h)^{3}$ $K^{-1}, \rho$ is the density, $K$ is the vertical diffusivity, $\Delta z_{k-1 / 2}=$ $\left(\Delta z_{k}+\Delta z_{k-1}\right) / 2, \rho_{k-1 / 2}=\left(\rho_{k-1} \Delta z_{k-1}+\rho_{k} \Delta z_{k}\right) /\left(\Delta z_{k}+\right.$ $\left.\Delta z_{k-1}\right)$, and $A$ and $B$ are the BEP and BEP+BEM implicit and explicit source terms, respectively. Two additional terms are needed in the diffusion equation to account for the modification of the gridcell volume and surface areas of the vertical surfaces due to the effect of buildings (Martilli et al. 2002). The parameter $s_{k}$ is the fraction of the vertical surface not occupied by buildings, and $v_{k}$ is the volume of the grid cell not occupied by buildings. If there are no buildings in a grid cell or no buildings reducing vertical surfaces, $s_{k}$ and $v_{k}$ are identically unity. By moving the time level $n+1$ terms to the left side and $n$ terms to the right side, we obtain

$$
\begin{aligned}
& {\left[\frac{-\Delta t}{v_{k} \rho_{k} \Delta z_{k}} \frac{s_{k-1 / 2} \rho_{k-1 / 2} K_{k-1 / 2}}{\Delta z_{k-1 / 2}}\right] C_{k-1}^{n+1}+\left[1-\frac{\Delta t}{v_{k} \rho_{k} \Delta z_{k}}\left(\frac{s_{k-1 / 2} \rho_{k-1 / 2} K_{k-1 / 2}}{\Delta z_{k-1 / 2}}+\frac{s_{k+1 / 2} \rho_{k+1 / 2} K_{k+1 / 2}}{\Delta z_{k+1 / 2}}\right)-A_{k} \Delta t\right] C_{k}^{n+1}} \\
& -\left[\frac{\Delta t}{v_{k} \rho_{k} \Delta z_{k}} \frac{s_{k+1 / 2} \rho_{k+1 / 2} K_{k+1 / 2}}{\Delta z_{k+1 / 2}}\right] C_{k+1}^{n+1}=C_{k}^{n}+B_{k} \Delta t+\left[\frac{-\Delta t}{v_{k} \rho_{k} \Delta z_{k}} s_{k-1 / 2} \rho_{k-1 / 2} K_{k-1 / 2} \alpha_{k-1 / 2}\right] \\
& -\left[\frac{\Delta t}{v_{k} \rho_{k} \Delta z_{k}} s_{k+1 / 2} \rho_{k+1 / 2} K_{k+1 / 2} \alpha_{k+1 / 2}\right] .
\end{aligned}
$$


At each horizontal grid point, the vertically discrete implicit Eq. (A2) reduces to a tridiagonal matrix problem $\mathbf{M X}=\mathbf{N}$ for $\mathbf{X}=C_{k}^{n+1}$, where $\mathbf{M}$ is a tridiagonal matrix and $\mathbf{N}$ is a vector containing the explicit terms. In the special case of $A$ and $B=0$, the implicit solver reduces to appendix $B$ of Hong et al. (2006). We have elected to keep the BEP and BEP+BEM implementation in the same general form in the YSU PBL parameterization as it is in the MYJ and BOU parameterizations, with the option for splitting various momentum, potential temperature, and mixing ratio sources between the implicit $A$ and explicit $B$ components. Some users may wish to force YSU with explicit $B$ sources only since it is a nonlocal closure scheme. With the general formulation in Eq. (A1), if a user wishes to force YSU with explicit sources only, the implicit $A$ source can be zeroed out and the corresponding sources can be put into the explicit $B$ source term.

\section{REFERENCES}

Ackerman, B., 1987: Climatology of Chicago area urban-rural differences in humidity. J. Climate Appl. Meteor., 26, 427-430, https:// doi.org/10.1175/1520-0450(1987)026<0427:COCAUR >2.0.CO;2.

Arya, S. P., 2001: Introduction to Micrometeorology. Academic Press, $402 \mathrm{pp}$.

Barlage, M., S. Miao, and F. Chen, 2016: Impact of physics parameterizations on high-resolution weather prediction over two Chinese megacities. J. Geophys. Res. Atmos., 121, 44874498, https://doi.org/10.1002/2015JD024450.

Bauer, T. J., 2020: Interaction of urban heat island effects and landsea breezes during a New York City heat event. J. Appl. Meteor. Climatol., 59, 477-495, https://doi.org/10.1175/JAMCD-19-0061.1.

Bauweraerts, P., and J. Meyers, 2019: On the feasibility of using large-eddy simulations for real-time turbulent-flow forecasting in the atmospheric boundary layer. Bound.-Layer Meteor., 171, 213-235, https://doi.org/10.1007/s10546-019-00428-5.

Bougeault, P., and P. Lacarrere, 1989: Parameterization of orographyinduced turbulence in a mesobeta-scale model. Mon. Wea. Rev., 117, 1872-1890, https://doi.org/10.1175/1520-0493(1989) 117<1872:POOITI $>2.0$. CO;2.

Chen, F., and Coauthors, 2011: The integrated WRF/urban modeling system: Development, evaluation, and applications to the urban environmental problems. Int. J. Climatol., 31, 273288, https://doi.org/10.1002/joc. 2158.

Ching, J., and Coauthors, 2009: National Urban Database and Access Portal Tool. Bull. Amer. Meteor. Soc., 90, 1157-1168, https://doi.org/10.1175/2009BAMS2675.1.

—_ and Coauthors, 2018: WUDAPT: An urban weather, climate, and environmental modeling infrastructure for the Anthropocene. Bull. Amer. Meteor. Soc., 99, 1907-1924, https://doi.org/10.1175/ BAMS-D-16-0236.1.

Chow, W. T. L., F. Salamanca, M. Georgescu, A. Mahalov, J. M. Milne, and B. L. Ruddell, 2014: A multi-method and multiscale approach for estimating city-wide anthropogenic heat fluxes. Atmos. Environ., 99, 64-76, https://doi.org/10.1016/ j.atmosenv.2014.09.053.
Cohen, A. E., S. M. Cavallo, M. C. Coniglio, and H. E. Brooks, 2015: A review of planetary boundary layer parameterization schemes and their sensitivity in simulating southeastern U.S. cold season severe weather environments. Wea. Forecasting, 30, 591-612, https://doi.org/10.1175/WAF-D14-00105.1.

Deardorff, J. W., 1972: Theoretical expression for the countergradient vertical heat-flux. J. Geophys. Res., 77, 5900-5904, https://doi.org/10.1029/JC077i030p05900.

Dudhia, J., 1989: Numerical study of convection observed during the winter monsoon experiment using a mesoscale two-dimensional model. J. Atmos. Sci., 46, 3077-3107, https://doi.org/10.1175/ 1520-0469(1989)046<3077:NSOCOD>2.0.CO;2.

Ek, M. B., K. E. Mitchell, Y. Lin, E. Rogers, P. Grummann, G. Gayno, and J. D. Tarpley, 2003: Implementation of Noah land surface model advances in the National Centers for Environmental Prediction operational mesoscale Eta model. J. Geophys. Res., 108, 8851, https://doi.org/10.1029/2002JD003296.

Gutiérrez, E., J. E. González, A. Martilli, R. Bornstein, and M. Arend, 2015: Simulations of a heat-wave event in New York City using a multilayer urban parameterization. J. Appl. Meteor. Climatol., 54, 283-301, https://doi.org/10.1175/JAMCD-14-0028.1.

Hage, K. D., 1975: Urban-rural humidity differences. J. Appl. Meteor., 14, 1277-1283, https://doi.org/10.1175/1520-0450(1975) 014<1277:URHD>2.0.CO;2.

Hammerberg, K., O. Brousse, A. Martilli, and A. Mahdavi, 2018: Implications of employing detailed urban canopy parameters for mesoscale climate modelling: A comparison between WUDAPT and GIS databases over Vienna, Austria. Int. J. Climatol., 38, e1241-e1257, https://doi.org/10.1002/joc.5447.

Hong, S.-Y., and H.-L. Pan, 1996: Nonlocal boundary layer vertical diffusion in a Medium Range Forecast model. Mon. Wea. Rev., 124, 2322-2339, https://doi.org/10.1175/1520-0493(1996) $124<2322$ :NBLVDI $>2.0 . \mathrm{CO} ; 2$.

— crophysics scheme (WSM6). J. Korean Meteor. Soc., 42, 129151.

_- Y. Noh, and J. Dudhia, 2006: A new vertical diffusion package with an explicit treatment of entrainment processes. Mon. Wea. Rev., 134, 2318-2341, https://doi.org/10.1175/MWR3199.1.

Iacono, M. J., J. S. Delamere, E. J. Mlawer, M. W. Shephard, S. A. Clough, and W. D. Collins, 2008: Radiative forcing by longlived greenhouse gases: Calculations with the AER radiative transfer models. J. Geophys. Res., 113, D13103, https://doi.org/ 10.1029/2008JD009944.

Janjić, Z. I., 1994: The step-mountain eta coordinate model: Further developments of the convection, viscous sublayer, and turbulence closure schemes. Mon. Wea. Rev., 122, 927-945, https://doi.org/ 10.1175/1520-0493(1994)122<0927:TSMECM>2.0.CO;2.

Jiménez, P., and J. Dudhia, 2012: Improving the representation of resolved and unresolved topographic effects on surface wind in the WRF Model. J. Appl. Meteor. Climatol., 51, 300-316, https://doi.org/10.1175/JAMC-D-11-084.1.

, — - J. F. Gonzalez-Rouco, J. Navarro, J. P. Montavez, and E. Garcia-Bustamante, 2012: A revised scheme for the WRF surface layer formulation. Mon. Wea. Rev., 140, 898-918, https://doi.org/10.1175/MWR-D-11-00056.1.

Knievel, J. C., G. H. Bryan, and J. P. Hacker, 2007: Explicit numerical diffusion in the WRF Model. Mon. Wea. Rev., 135, 3808-3824, https://doi.org/10.1175/2007MWR2100.1.

Kusaka, H., and F. Kimura, 2004: Coupling a single-layer urban canopy model with a simple atmospheric model: Impact on 
urban heat island for and idealized case. J. Meteor. Soc. Japan, 82, 67-80, https://doi.org/10.2151/jmsj.82.67.

- H. Kondo, Y. Kikegawa, and F. Kimura, 2001: A simple singlelayer urban canopy model for atmospheric models: Comparison with multi-layer and slab models. Bound.-Layer Meteor., 101, 329-358, https://doi.org/10.1023/A:1019207923078.

Kuttler, W., S. Weber, J. Schonnefeld, and A. Hesselschwerdt, 2007: Urban/rural atmospheric water vapour pressure differences and urban moisture excess in Krefeld, Germany. Int. J. Climatol., 27, 2005-2015, https://doi.org/10.1002/joc.1558.

Lim, K.-S. S., and S.-Y. Hong, 2010: Development of an effective double moment cloud microphysics scheme with prognostic cloud condensation nuclei $(\mathrm{CCN})$ for weather and climate models. Mon. Wea. Rev., 138, 1587-1612, https://doi.org/ 10.1175/2009MWR2968.1.

Liu, X., X.-X. Li, S. Harshan, M. Roth, and E. Velasco, 2017: Evaluation of an urban canopy model in a tropical city: The role of tree evapotranspiration. Environ. Res. Lett., 12, 094008, https://doi.org/10.1088/1748-9326/AA7EE7.

Martilli, A., A. Clappier, and M. Rotach, 2002: An urban surface exchange parameterisation for mesoscale models. Bound.-Layer Meteor., 104, 261-304, https://doi.org/10.1023/A:1016099921195.

_- S. Grossman-Clarke, M. Tewari, and K. W. Manning, 2009: Description of the modifications made in WRF.3.1 and short user's manual of BEP. NCAR RAL Tech. Note, 24 pp., https://ral.ucar.edu/sites/default/files/public/product-tool/ Multi_layer_UCM.pdf.

Meier, F., D. Fenner, T. Grassmann, M. Otto, and D. Scherer, 2017: Crowdsourcing air temperature from citizen weather stations for urban climate research. Urban Climate, 19, 170-191, https://doi.org/10.1016/j.uclim.2017.01.006.

Mellor, G. L., and T. Yamada, 1982: Development of a turbulence closure model for geophysical fluid problems. Rev. Geophys. Space Phys., 20, 851-875, https://doi.org/10.1029/ RG020i004p00851.

Murphy, A. H., B. G. Brown, and Y.-S. Chen, 1989: Diagnostic verification of temperature forecasts. Wea. Forecasting, 4, 485-501, https://doi.org/10.1175/1520-0434(1989)004<0485: DVOTF $>2.0 . \mathrm{CO} ; 2$.

Noh, Y., W. G. Cheon, S.-Y. Hong, and S. Raasch, 2003: Improvement of the K-profile model for the planetary boundary layer based on large eddy simulation data. Bound.-Layer Meteor., 107, 401-427, https://doi.org/10.1023/A:1022146015946.

Oke, T., 1976: The distinction between canopy and boundary-layer urban heat islands. Atmosphere, 14, 268-277, https://doi.org/ 10.1080/00046973.1976.9648422.

_- 1982: The energetic basis of the urban heat island. Quart. J. Roy. Meteor. Soc., 108, 1-24, https://doi.org/10.1002/ qj.49710845502.

Sailor, D. J., M. Georgescu, J. M. Milne, and M. A. Hart, 2015: Development of a national anthropogenic heating database with an extrapolation for international cities. Atmos. Environ., 118, 7-18, https://doi.org/10.1016/j.atmosenv.2015.07.016.

Salamanca, F., A. Krpo, A. Martilli, and A. Clappier, 2010: A new building energy model coupled with an urban canopy parameterization for urban climate simulations-Part I. Formulation, verification, and sensitivity analysis of the model. Theor. Appl. Climatol., 99, 331-344, https://doi.org/ 10.1007/s00704-009-0142-9.

_- A. Martilli, M. Tewari, and F. Chen, 2011: A study of the urban boundary layer using different urban parameterizations and high-resolution urban canopy parameters in WRF. J. Appl. Meteor. Climatol., 50, 1107-1128, https://doi.org/ 10.1175/2010JAMC2538.1.

_- M. Georgescu, A. Mahalov, M. Moustaoui, and M. Wang, 2014: Anthropogenic heating of the urban environment due to air conditioning. J. Geophys. Res. Atmos., 119, 5949-5965, https://doi.org/10.1002/2013JD021225.

_, Y. Zhang, M. Barlage, F. Chen, A. Mahalov, and S. Miao, 2018: Evaluation of the WRF-urban modeling system coupled to Noah and Noah-MP land surface models over a semiarid urban environment. J. Geophys. Res. Atmos., 123, 2387-2408, https://doi.org/10.1002/2018JD02837.

Shin, H. H., S.-Y. Hong, Y. Noh, and J. Dudhia, 2013: Derivation of turbulent kinetic energy from a first-order nonlocal planetary boundary layer parameterization. J. Atmos. Sci., 70, 17951805, https://doi.org/10.1175/JAS-D-12-0150.1.

Skamarock, W. C., J. B. Klemp, J. Dudhia, D. O. Gill, D. M. Barker, W. Wang, and J. G. Powers, 2005: A description of the Advanced Research WRF version 2. NCAR Tech. Note NCAR/TN468+STR, 88 pp., https://doi.org/10.5065/D6DZ069T.

Stewart, I. D., and T. R. Oke, 2012: Local climate zones for urban temperature studies. Bull. Amer. Meteor. Soc., 93, 1879-1900, https://doi.org/10.1175/BAMS-D-11-00019.1.

Tewari, M., and Coauthors, 2004: Implementation and verification of the unified Noah land surface model in the WRF Model. 20th Conf. on Weather Analysis and Forecasting/16th Conf. on Numerical Weather Prediction, Seattle, WA, Amer. Meteor. Soc., 14.2A, https://ams.confex.com/ams/pdfpapers/69061.pdf.

Tiedtke, M., 1989: A comprehensive mass flux scheme for cumulus parameterization in large-scale models. Mon. Wea. Rev., 117, 1779-1800, https://doi.org/10.1175/1520-0493(1989)117<1779: ACMFSF $>2.0 . \mathrm{CO} ; 2$.

Troen, I., and L. Marht, 1986: A simple model of the atmospheric boundary layer sensitivity to surface evaporation. Bound.-Layer Meteor., 37, 129-148, https://doi.org/10.1007/BF00122760.

Tucker, S. C., and Coauthors, 2006: Relationships of coastal nocturnal boundary layer winds and turbulence to Houston ozone concentrations during TexAQS 2006. J. Geophys. Res., 115 , D10304, https://doi.org/10.1029/2009JD013169.

Xie, B., J. C. H. Fung, A. Chan, and A. Lau, 2012: Evaluation of nonlocal and local planetary boundary layer schemes in the WRF model. J. Geophys. Res., 117, D12103, https://doi.org/ 10.1029/2011JD017080.

Zhang, C., Y. Wang, and K. Hamilton, 2011: Improved representation of boundary layer clouds over the southeast Pacific in ARW-WRF using a modified Tiedtke cumulus parameterization scheme. Mon. Wea. Rev., 139, 3489-3513, https:// doi.org/10.1175/MWR-D-10-05091.1. 